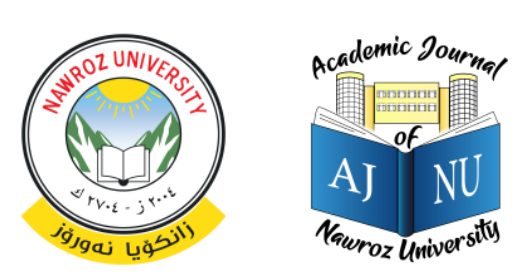

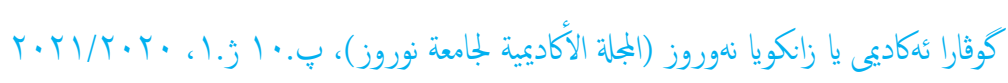
حقوق الطبع والنشر @2017. هذه مقالة الوصول اليها مفتوح موزعة تحت رخصة e-ISSN: 2520-789X ،CC BY-NC-ND 4. 0. - المشاع الايداعي النسبي https://doi.org/10.25007/ajnu.v10n1a1106

\title{
اشكالية اختيار رئيس الحكومة في إقليم كوردستان - العراق دراسة تحليلية مقارنة
}

د. عثان علي حسن ويسي، القأون المستوري، برلمان اقليم كردستان، العراق

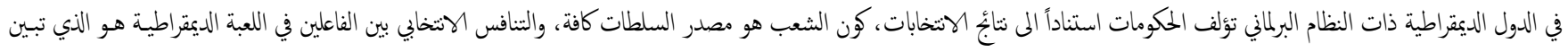

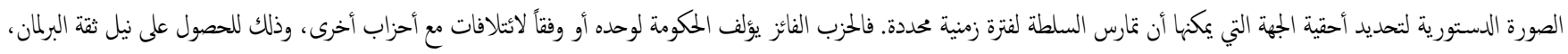

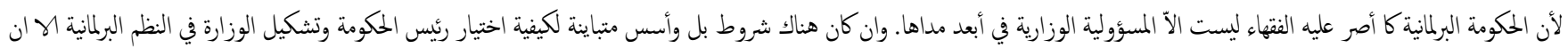

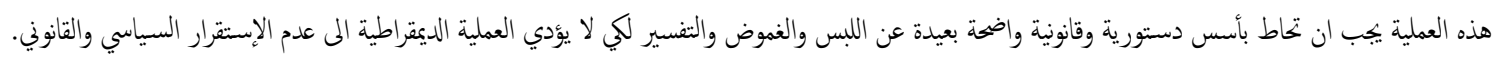

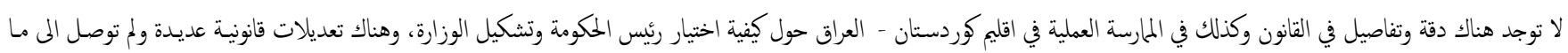
يجب ان تكون عليه، وذلك هو السبب الرئيسي في هذا البحث لكي يكون يبين القواعد الدستورية المفيدة بهذا الصددد والحيلولة دون افساح المجال أمام القواعد الغير مبررة بهذا الشأن.

1

ومن الناحية العملية فان هناك تداخلات وتناقضات وعدم الإستقرار بين القواعد المنظمة لهذا الموضوع.

2.1 مشكلة البحث

ثنائية السلطة الننفيذية تركية خاصة بالنظام البرلمانى من الناحيتين النظرية والعملية، ولكل من رئيس الدولة ورئيس الحكومة مركز خاص بكل منها، وكيفية اختيار رئيس الحكومة تلعب دوراً أساسياً في العلاقة الدستورية والقانونية الموجودة بين البرمان ورئيس الدولة، خصوصاً في ظل النظام السياسي ذات النعدد الحزبي وغيرها من العوامل النظرية والعملية.

وفي إقليم كوردستان، وبعيداً عن مبدأ المحاصصة وتقسيم المناصب، اشتركت الاحزاب والمكونات في تأليف الحكومة عملاً بقواعد الحكومة التوافقية أو الأئلافية، بعيدا عن مبدأ المحاصصة وتقسيم المناصب أو الإثكالية للحيلولة دون الخوض في الخلل الأمني أو السياسي أو التقسيم الإداري حيث له معنى سيء في ذاته وايياد خلافات مع كل انتخابات برلمانية، مع ما يرافق ذلك من اعتبارات

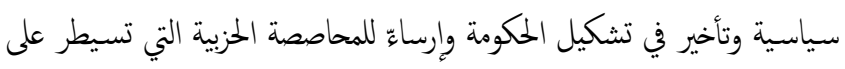

العملية السياسية.

وعليه ان هناك اشكليات في التطور القانوني للسلطات وتقصير في النصوص في إقليم كوردستان وهذا بدوره ينعكس على الممارسة الواقعية. لذ تنساءل هل نحن
في إقليم كوردستان- العراق، ومنذ تأسيس المؤسسات الدستورية في الاقليم، لم ككتمل بعد أوجه تنظيم السلطات والعلاقات المنبادلة فيه بينها، ولم تحدد لحد الآن المبادئ التي ترنكز عليها مارسة السلطة في الإقليم تحديداً واضحاً، خصوصاً في وليم غياب وجود الدستور. من احدى القواعد الدستورية الأساسية هي كيفية اختيار رئيس الحكومة، اذ جرى العمل ومنذ عام 1992 على اختيار وتسمية رئيس المكومة باتجاهات غير ثابتة، ومن جهة اخرى جرت تعديلات عديدة على كيفية ترشيح وتسمية وتكليف

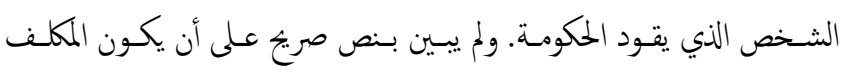
بتشكيل الحكومة هو من حزب الفائز الأول أو من كتلة ذات الأكثرية أو من

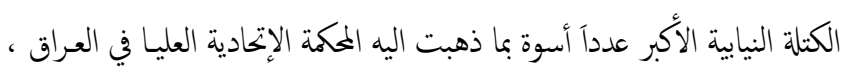
هذا البحث يلقي الضوء على هذه الجوانب وغيرها. 1.1

ان رئيس المكومة يتمع بمركز دستوري وقانوني أساسي في النظام البرلماني، وبما أن هذا النظام هو المطبق في العراق وفي إقليم كوردستان، نرى مـن الضروري أن نسلط الضوء على الحدود النظرية ومدى تطبيقها لكيفية اختيار رئس الحكومة في إلإقليم واشكليانها، خصوصاً في غياب الدستور والتعديلات المنكررة في القوانين المتعلقة بها. فن الناحية النظرية فان هذالموضوع لم يتم تناوله من قبل الباحثين، 


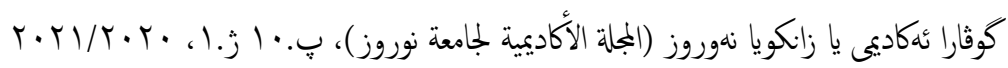

الحكومة يجب أن تكون قد تم اختيارها على أساس الثقة البرلمانية1. لأن النظام

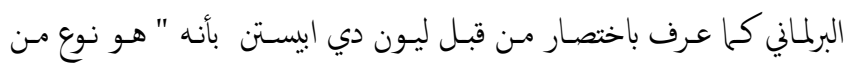
الديمقراطية الدستورية التي تنشا السلطة التنفيذية من السلطة التشريعية وتكون مسؤولة أماما"2، فالنظام البرلماني قائم على الفصل الناعم والمتوازن بين السلطتين، نظرًا لأن السلطة التشريعية والتنفيذية ليست مستقلة عن بعضها البعض بل تؤثران دائمًا على بعضها البعض، ويطلق عليه بانه نظام تعاون أو حتى تداخل القوى3. وفي رأينا أن النظام البرلماني يقوم على أساس فكرة الفصل المرن بين السلطات مشوباً بتنظيم وروح التعاون والنوازن والمساواة والتداخل والرقابة المتبادلة بين السلطتين. وأساساً فان السلطة التنفيذية في النظام البرلماني كان يتولاها رئيس الدولة، ولكنها انتقلـت عمليـاً وتـدريجياً الى المكومـة فيها بعـد. وان الأتصـال بـين السـلطنين الرئيسيتين كان يتم بواسطة الحكومة التي يعينها رئيس الدولة بعد الحصول على ثقة

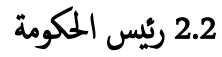

في النظام البرلماني يوجد رئيس الدولة ورئيس الحكومة كمانصب تنفيذية عليا، وبما أن رئيس الدولة يعد رئيساً للسلطة التنفيذية ولكنه غير مسؤول سياسياً، من ثم وجب انتقال السلطة الفعلية لرئيس الحكومة، بوصفه المسؤول عن ممارسة سلطة

التنفيذية امام البرلمان الذي يملك حق المراقبة عليها5. اذن السلطة التنفيذية في النظام البرلماني هي الوزارة - الحكومة التي تتكون من وزراء ويرأسها رئيس مجلس الوزراء (رئيس الحكومة أو رئيس الحكومة)، والحكومة تجنع برئاسة رئيس الحكومة في شكل هيئة تضامنية جاعية هي مجلس الوزراء. وبجلس الوزراء يعد تنظياً دستورياً للوزارة ويعتبر من الخصائص الهامة التي تيميز بها النظام البرلماني(6). فالمكومة هي العضو الفعال في السلطة التنفيذية وتزاول الإختصاصات الدستورية للسلطة التنفيذية في الواقع، ورئيس الدولة

$$
\text { يمارس السلطة بواسطة الوزارة ومجلس الوزراء (7). }
$$

ويتولى رئيس الحكومة رئاسة الحكومة الوزارة، و يستعمل في اللغة الإنجليزية مصطلحات ومرادفات لرئيس المكومة في النظام البرلماني، على الرغز من المصطلحات الأخرى مثل الوزير الأول ، رئس الحكومة ، المستشار ، رئس الحكومة ، رئيس المجلس (الوزراء) ، ويتم تطبيق مصطلح وزير الدولة أو رئيس الحكومة أو الوزير في بعض الأحيان في سياقات لغوية وثقافية ختلفة. اذن رئس المكومة هو الذي يعتبر الرئيس الفعلي للدولة بفضل صفته التمثيلية
بحاجة المى اصدار قانون خاص لتنظيم الحكومة بكافة أبعاده أم في ماذا يكمن

3.1 نطاق البحث

إن نطاق البحث يدور في محيط تعريف الحكومة في النظام البرلمانى، بدعاً من تسمية وإختيار رئيس احكومة وكذلك دور الأحزاب في تشكيل الحكومة، كل ذلك مقارنة مع الوضع القانوني في إقليم كوردستان، وفي افق مقارن لإبراز نقاط الضعف والقوة وبيان الخلل الموجود في هذه العملية بهدف إزالته واستيعاب مـا يستنتج منه وما يوصى بشأنه.

4.1 فرضية البحث

ان فرضية البحث تكمن في نقطة دستورية رئيسية وهي: المى مدى اختيار رئيس الحكومة في اقليم كوردستان متطابقة مع القواعد الستورية المتبعة في النظام

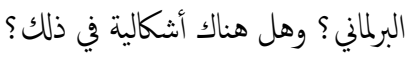

\section{1 منهجية البحث}

لقد اخذنا في هـا البحث بالمنهج التحليلي المقارن معتمدين في ذلك الأسس النظرية للنظام البرلماني والتطورات القانونية في اقليم كوردستان العراق ، وذلك لكي نصل الى الهدف المرجو من البحث

6.1

لقد قنا بتقسيم البحث الى مبحثين، المبحث الأول نتناول الدراسة النظرية لكيفية اختيار رئيس الحكومة في النظام البرلماني، وفي الثاني فقد بحثنا اختيار رئيس الحكومة في بعض دول ذات النظام البرلماني وتطرقنا المى الأشكاليات الأساسية في اقليم كوردستان في ضوء القواعد الأساسية التي يتضمنها النظام البرلماني، ثم جاء البحث بخاتمة وأهم الإستنتاجات والتوصيات المفيدة بهذا الشأن.

\section{2. كيفية اختيار رئيس الحكومة في النظام البرلماني}

في هذا المبحث نقوم بدراسة رئيس الحكومة وموقعه الدستوري في النظام البرلماني وبيان الأسس الرئسية المتبعة لإختيار رئيس الحكومة ، وكالآتي:

\section{2 السلطة التنفية في النظام البرلماني}

ان رئيس الدولة والبرلمان في الحكومات البرلمانية لما دوراً أساسياً في عملية اختيار رئس الحكومة وكيفة تشكيلها، فعند وجود انتخابات جديدة أو اقلالة الحكومة القديمة أو استقالتها أو وفاة رئيسها يقوم رئيس الدولة أو رئيس البرلمان والبرلمان باختيـار رئيس المكومهة الجديد، وان المبـدأ الأول للايمقراطية البرلمانية هـو أن 


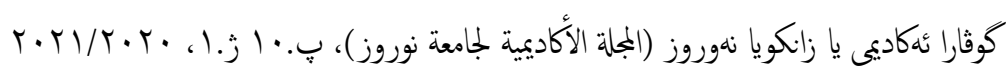

في الأظمة الحكومية البرلمانية، يكون مجلس الوزراء ثنائيًا مزدوجًا وهما رئيس الحكومة و الوزراء، ورئيس الحكومة هو رئيس مجلس الوزراء ـ ووفقًا لنظرية القانون الدستوري الكلاسيكي، يتتع رئيس الحكومة بوضع قانوني. كما هي حال الوزراء، لذلك رئيس الحكومة لا يخظى إلا بالأول من بين المتساوين، من الناحية القانونية فقط ، أما من الناحية السياسية، أصبح رئس الحكومة أكثر أهمية من الوزراء الآخرين. واتفاقًأمع ذلك هناك علاقة هرمية بين رئس الحكومة والوزراء، وليس المساواة، فالوزراء يكونون تحت سلطة رئيس الحكومة ويعتمد تعيين الوزراء كلياً على إرادة رئيس المكومة14. وفي الدساتير البرلمانية الجديدة ، هذا المنصب الرفيع معترف به لرئيس الحكومة، يككنا أن نقول بوضوح أنه في الأظمة الحكومية البرلمانية، يكون رئيس المكومة هو رئيس المكومة وهو في وضع أعلى من الوزراء الآخرين ومن حيث وضعه القانوني والجنائي والمالمي يعامل رئس الحكومة كوزير 15. فني النظام البرلماني يرأس الوزراء رئيس الحكومة الذي يعتبر الشخص الثاني في رئاسة السلطة التنفيذية، وبالرغز من أنه يتولى رئاسة الوزارة ألاّ إنها تكون هيئة جاعية ومتساوية يناط لها مارسة الوظيفة التنفيذية 16. وعليه، من الناحية الناريخية، لم يكن لرئيس الحكومة قبل سنة 1700م أي مركز قانوني بميزه عن بقية المنفذين بل كان يشغل على العكس من ذلك مركزاً فعلياً، وحتى بعد ثورة 1688 كان تعيين رئيس الوزارة حقا من حقوق الملك الشخصية، وليس للبرلمان رغز زيادة سلطنه ونوذه اجبار الملك على اختيار الوزراء من الأغليبة.17. وبرزت عناصر هذا المركز في عهد الملكة (آن) 1702 - 1714، فرويداً رويداً تغيرت الظروف وأصبح رئيس المكومة حاك؟ البلاد ورئيسها الفعلي، خصوصاً من الوجتة الفعلية، وان الدستور الحديث كما يقول مونتاج يجعل رئيس الحكومة أقوى رجل في الدولة، خصوصاً حينا يقود الأغلبية البرلمانية ولا يستسلم لها أو يمثل بسهولة لرأها، ويصبح يوماً فيوماً أقرب الناس الى الشعب بل ويصبح نائبًا لأمته(18). اذن فقبل ان تستقر أسس النظام البرلماني، فان اختيار رئيس الحكومة في انكلترا كانت محصورة بالأختيار المطلق للملك على أساس من الثقة المتبادلة بنيها، وبقاءه في الحكى مرتبط ايضا برضا الملك. وظهر منصب رئس الحكومة في بريطانيا سنة 1720م، وتطورت تدريجياً وبرزت أهمية هذا المنصب والإختصاصات الممنوحة لرئيس الحكومة الى ان تم الإعتراف به رسمياً في عهد الملك ادوارد السابع 1905، وكان التاج يتدخل في تشكيل الوزارات حتى صدور قانون الإصلاح الإنتخابي عام 1832، وأصبح وسيطرته على الحزب الذي تكون له الأغلبية في مقاعد البرلمان(9) على الأربح. وهو روح الوزارة، والعامل الرئيسي لمجلس الوزراء، واذا نظرنا الى المسألة من الناحية التأريخية فأننا نجد أن مجلس الوزراء لم يكن من المستطاع أن يتكون بدونه، ومن الناحية السياسية فأن الوزارة كلها تسقط بسقوطه.(10) وفي العراق يتألف مجلس الوزراء من رئيسه ونوابه والوزراء، و و (رئيس الحكومة هو المسؤول التنفيذي المباشر عن السياسة العامة للدولة، والقائد العام للقوات المسلحة، يقوم بإدارة مجلس الوزراء، ويترأس اجتماعه، وله الحق بإقالة الوزراء، بموافقة مجلس النواب) (12). ويمارس مجلس الوزراء تخطيط وتنفيذ السياسة العامة للدولة، والخطط العامة، والإشراف على عمل الوزارات والجهات غير المرتبطة بوزارة (13). ولا يوجد مثل هذا التعريف والتشخيص لرئيس مجلس الوزراء في القوانين المختصة في اقليم كوردستان. 3.2 موقع رئيس الحكومة في النظام البرلماني 


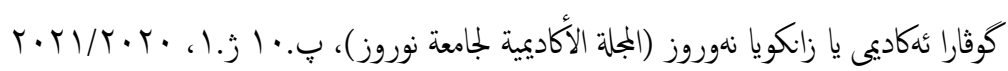

(3) لمجلس الوزراء نرى بأنه اضافة الى ضرورة تعديل ذلك وازالة النعارض، الأولوية تكون لقانون مجلس الوزراء كونه قانوناً خاصاً وهو يعد من القوانين

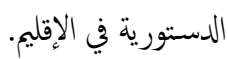

وعلي،، فالدول التي تأخذ بالنظام البرلماني تعمل على إختيار الوزراء من داخل البرلمان، وان كانت هذه القاعدة ليست مطلقة، إذ يككن اختيارد الوزراء من خارجه. واذا كان اختيار الوزراء من اعضاء البرلمان، فإن هناك تشكيلات وزارية قد تضم اعضاء فنيين من الذين تتوافر فيهم خبرات معينة خارج اعضاء البرلمان كرجال الجيش أو البحرية أو الادارة العامة أو من رجال الأعال وغيرهم (30). الاّ إننا نرى بأن من الأفضل أن نأخذ الوضع السياسي والحزبي والعرفي لكل دولة ونظام

الحكى فهيا بنظر الإعتبار في حال الإتيان بالمحع بين الوزارة والنيابة أو بالعكس.

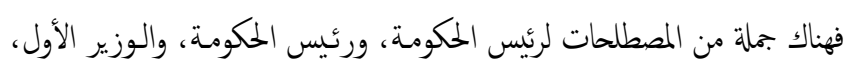
وأعضـاء المكومهـة، ورئيس المكومـة، ومجلس الـوزراء، كل في سـياق مامـهـ

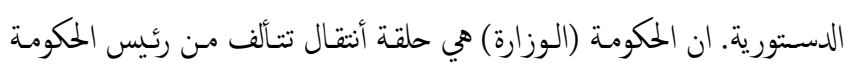

ومجلس الوزراء والوزراء.

\section{2 إستناد الحكومة ومنهاجما الوزاري المى ثقة البرلمان}

الأكزية الحزبية داخل البرلمان تـدور مع ضمان منهج الثقة بالحكومة ومنهاجهـا

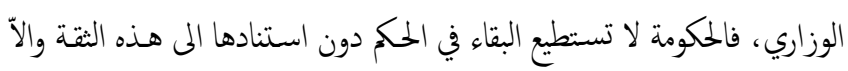
اسقطها البرلمان ، وبالتالي يصبح لزاماً على رئيس الدولة أو الجهة المكلفة بالتسمية النكليف مرة أخرى عن رئيس ووزراء حكومة جديدة لكي تحوز على ثقة البرلمان وتنعم بتأييده، ونبحث ذلك في الفقرتين الآتيين:

أ- الحصول على ثقة البرلمان: ان البرلمان هو الذي يعطي الموافقة والرضاء على

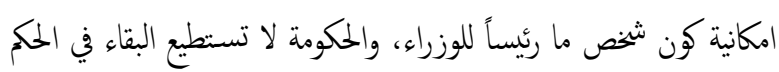
دون استنادها الى هذه الثقة وال اسقطها البرلمان. (فلا يؤدي النظام البرلماني إلى الاستقطاب وييتاج الحزب الفائز بالانتخابات دائمًا إلى دع برلماني، وتتولى الأحزاب الخاسرة وظيفة المعارضة)31. وبرلمان كوردستان هو الذي يمنح الثقة للسلطة التنفيذية ويسحها منه (32). ولكن الدستور والقوانين العراقية ذات الصلة لم تعالج مسألة استقالة رئس الحكومة في الحكومة العراقية (33).

ب- - حصول المنهاج الوزاري على ثثة البرلمان: مجلس الوزراء هو حجر الزاوية في السلطة التنفيذية في النظام البرلمان، وهو الذي يضع السياسة العامة للحكومة، وتخضع تصرفات الوزراء لرقابة البرلمان سواء من حيث
سارياً كقاعدة ملزمة عام 1910، الاّ ان العرف الدستوري يقضي من الملك

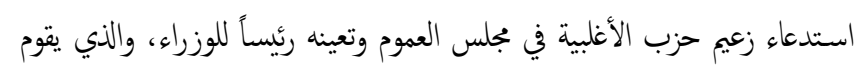
باختيار أعضاء الوزارة من غالبية أعضائها من حزبه ${ }^{19}$ أما في حالة عدم فوز أحد الأحزاب بأغلبية في مجلس العموم، فعلى الملكة القيام بتشكيل حكومة ائتلافية من الأحزاب الرئيسة في مجلس العموم شريطة أن تخظى بثقة البرلمان 20. في النظام البرلماني الديمقراطي الثابت بشكل عام، فان عملية اختيار رئيس الحكومة

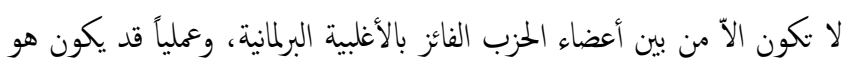
زعيم هذا الحزب 21. و رئيس المكومة قد يكون عضواً في البرلمان، إن منطق النظام البرلماني يقتي أن يكون أعضاء في مجلس الوزراء بما فيهم رئيس الحكومة أعضاء في البرلمان 22. لكن وبخلاف ذلك اذا كان النظام البرلماني يستند المى فكرة التعاون بين السلطتين فلا يعني ذلك الإتفاق حول اجازته للجمع بين عضوية الججالس النيابية والحكومة، وهناك اختلاف للرأي في النظام البرلماني، وأنتسم الدساتير والفقه عليها 23 . فالرأي يقضي بعدم الجمع بين الوزارة والنيابة، وذلك لكي يتولى ادارة شؤون الدولة

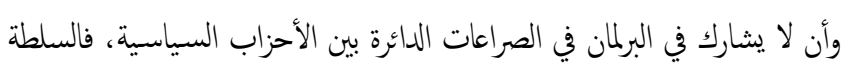
التنفيذية يجب أن تكون فوق الصراعات الحزبية، وهذا يؤدي الى تقوية الفصل

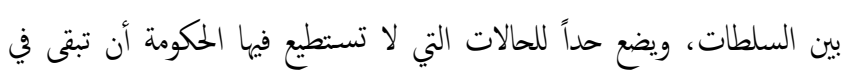
السلطة الم بسب الدئ الذي تعمد عليه من اعضاءها لكونهم نواباً في البرلمان. وكذلك فان عدم الجمع يساعد على تحقيق الأستقرار الحكوي، كونه يحد من نزعة النواب سحب الثفة عن الحكومة بهدف الدخول في حكومة جديدة(24.). في العراق لا يجوز الجمع بين النيابة وأي عمل أو منصب رسمي آخر 25. وكذلك في النظام البرلماني لإقليم كوردستان (لايجوز الجمع بين عضوية البرلمان والوظائف العامة ويعتبر الموظف العام مستقيلاً من وظيفته اعتباراً من أدائه اليمين أمام البرلمان وعليه اشعار سكرتارية البرلمان بموقفه الوظيفي)(26). وكذلك (لايجوز الجمع بين عضوية البرلمان وعضوية أحد الجمالس المنتخبة المرتبطة بدوائر ومؤسسات حكومة الاقليم وعلى العضو أن يختار أحد المجلسين خلال مدة ثمانية أيام من تأريخ اعلان نتيجة الانتخاب وإن لم يفعل يعتبر مختاراً لعضوية هذا البرلمان ويبلغ البرلمان بذلك)(27). هكذا وعند تقلد العضو منصباً وزارياً يعتبر مستقيلاً من عضوية

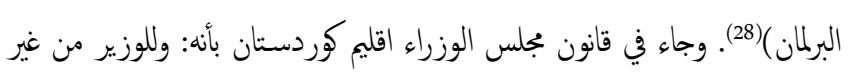

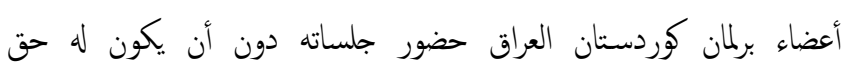
التصويت(29). وفي هذه الاختلافات بين قانون رخ (1) برلمان كوردستان ورقز 


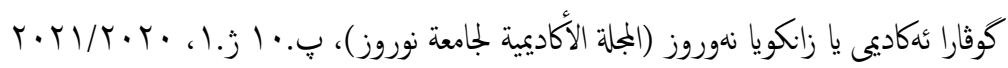

الوقت وفي نفس الاتجاه. وإذا لم يكن بعض الأعضاء حاضرين في الاجتماع أو عارضوا هذا القرار ، فلا يكن لمجلس الوزراء اتخاذ قرار. لهذا السبب ، فبان القرارات التي يتخذها مجلس الوزراء هي المعاملات الجماعية من حيث نظرية الإجراءات القانونية4.40 فالوزارة وحدة لا تتجزأ وقراراتها تعتبر جاعية بالرغز مسن صدورها من الأغلبية. والوزير الذي يريد أن يعني نفسه من مسؤولية أي قرار يصدر من مجلس الوزراء ليس أمامه من سبيل الوأن يستقيل من الوزارة (41). ويعقد المجلس اجتاعاته برئاسة رئس الحكومة ولكن يجوز أن يخضر- رئيس الدولة الإجتاع وتكون له رئاسة ومن ثخ ادارة المداولات والحوار فيه، وله التعبير عن رأي في المسائل المعروضة على المجلس، الها أنه ليس له حق التصويت اذا قرر المجلس التصـويت على موضـوع معروض عليه وذلك انسجاماً مع مبـدأ عدم مسـؤولية رئـيس الدولة حيـث ان الـوزارة هي الـتي تتحمـل المسـؤولية أمـام

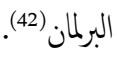
أما الأستاذ ليلة فانه يذهب الى أن اجتاع مجلس الوزراء يتخذ شكلين، فهو يسمى مجلس الوزراء اذا حضرهه رئيس الدولة، واذا لم يخضره يسمى مجلس الوزارة، وفي حالة حضور رئيس الدولة الإجتماع تكون له الرئاسة وتوجيه المناقشة وابداء رأيه في المسائل المعروضة، ولكن كونه غير مسؤول سياسياً فانه لا يككن ان يدلي بصوته وقت اخذ الأراء، وهكذا مجلس الوزراء هيئة، لها يكانها الذاتي، ويؤدي الى وحدة قانونية لها سلطة اصدار القرارات وادارة شؤون الدولة وتوجيه سياستها33. ونرى ان هذا الرأي يتفق مع روح هـا النظام خصوصاً في النظام

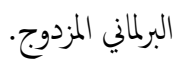

مشروعيتها وموافقتها للقانون، أم من حيث ملاءمتها وصلاحيتها لتحقيق ما صدرت من أجله (34). اذن يأمر رئيس الحكومة اعضاء حكومته بتحضير عناصر برنامج العمل الحكوي على ضوء قواعد عامة محددة مسبقاً وخطوط عمل أساسية واضحة، ويتم ذلك من خلال أدوات مستندة من قبل قطاعات النشاط المختلفة فيا يخص التوازنات الإقتصادية والإجتماعية والثقافية والتربوية... الحُ. من حيث المبدأ فان برنامج الحكومة لا يكن أن يظهر فيه إلا الأعال أو الإجراءات العامة أو الأولية التي تقررها الحكومة، وذلك مع الاشارة الى الأهداف المرجوة منها وشروط القيام بها والمدة الزمنية لتحقيقها. ان المثرع العراقي لدستور 2005 قد طلب للحصول على منح الثقة لرئيس بجلس الوزراء والمنهاج الوزاري، الأغلبية المطلقة لأعضاء مجلس النواب (35). ويعرض رئيس الحكومة المكلف اسهاء أعضاء وزاراته والمنهاج الوزاري على مجلس النواب، ويحال المنهاج الوزاري الى لجنة خاصة يرأسها أحد نائبي رئيس البرلمان لإعداد تقرير يقدم المجلس قبل التصويت عليه، وتعد الوزارة حائزة على ثقة البرلمان عند الموافقة على المنهاج الوزاري والوزراء منفردين 36. وفي اقليم كوردستان يمارس مجلس الوزراء صلاحية (وضع السياسة العامة للإقليم والإشراف عـلى تنفيـذها وفقـاً للقـوانين المرعيـة بعـد اقرارهـا مـن قبـل برلمـان كوردستان- العـراق)، وهو المسؤول عن (توجيه وتنسيق اعـال الوزارات والجهات التابعة لها والهيئات والمؤسسات العامة ومتابعة أعالها)(37). ونظراً لأن الحكومة هي المسؤولة سياسياً أمام البرلمان فإنها هي التي تتولى رسم السياسة العامة للحكومة (38). وان الحكومة (الرئيس وأعضاءها) مسؤلون باختصاصاتهم وبرنامج الحكومة وأسباب القرارات والتصرفات التي تقع في مجال اختصاصاتها(39). هذه المواد تدل على أن المسؤولية السياسية للحكومة تشمل رئيس الحكومة وأعضاءها ومنهاجما الوزاري. لكن لم يتم وضع قاعدة قانونية دستورية يقضي بذلك، ولم يطرح المهناج الوزاري على البرلمان للدراسة والحصول على ثقته، وقد تمت قراءة الخطوط العامة فقط في كل الكابينات الوزارية للإقليم، وذلك خلافا لما عليه الأصول الدستورية في النظام البرلماني.

\section{2 العلاقة التنظيمة الدستورية بين رئس الحكومة وبجلس الوزراء} يجمت رئيس الحكومة والوزراء لتشكيل لجنة ذات سلطة مشتركة لصنع القرار وهو مجلس الوزراء، وهو هيئة جاعية مؤلفة من الرئيس والوزراء ـ لذلك كهيئة جاعية ، يككن لمجلس الوزراء اتخاذ القرارات بإعلان إرادة بميع أعضائه في نفس بـ 


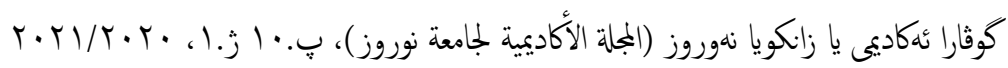

وفي فرنسا ان الحكومة تحدد السياسة العامة وتديرها، وهو تسيطر على الإدارة والقوات المسلحة، اما رئيس الحكومة يدير أعحال الحكومة، وييوز أن يفوض الوزارو في بعض سلطاته، ويكن أن ينوب عن رئيس الجمهورية بصفة إستثنائية في رئاسة مجلس الوزراء بموجب تفويض صريح ومن خلال جدول أعماله وأن أعحال رئيس الحكومة يوقعها الوزراء المكلفون بتنفيذها اذا استوجب ذلك (50). ومع وجود العديد من النصوص فإن الصعوبات الدستورية لا زالت قائمة في الدول ذات النظام البرلماني اذ ان النصوص الدستورية لا تتحدث عن هذه العلاقة ال قليلاً وهي في التطبيق لا تتجاوز حدود التقاليد الدستورية

\section{2 القواعد المتبعة لأختيار رئيس الحكومة}

نبين قواعد واصول اختيار رئيس الحكومة باختلاف صوره بين الدول، ونبحث في ذلك وكالآتي:

\subsection{2 أسس اختيار رئيس الحكومة في النظام البرلماني}

العلاقة بين رئس الدولة ورئيس الحكومة أو الوزارة بصفة عامة قد تحددها نصوص دستورية كما هو الغالب وقد يحددها العرف الدستوري كما هو الحال في

$$
\text { بريطانيا، ولكنها ليست ملاقة متينة في مجعها (51). }
$$

لرئيس الدولة في النظام البرلماني أهمية كبيرة في حفظ التوازن بين السلطنين، كحق تعيين وعزل الوزراء وحق الحل الرئاسي للبرلمان 52 ـ فعملية اختيار رئيس بئ بئي المكومة واختيار الوزراء الآخرين الذين يشكلون الحكومة تسمى عملية تشكيل الحكومة، الغرض منها اختيار وتعيين رئيس وزراء و مجلس الوزراء الذي يتمتع بثقة

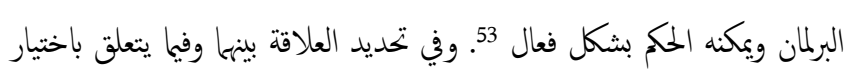

$$
\text { رئس الحكومة يوجد الحلات الآتية: }
$$

1.1.6.2 الإختيار على أساس المعيار الشخصي

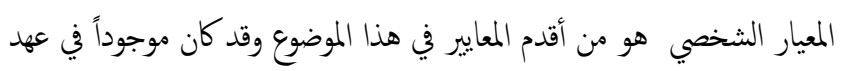
الملكية المطلقة، حيث يختار رئس الحكومة والوزراء على اساس الثقة الشخصية، ولكن هذا الإعتبار اخذ بالتلاشي بعد توسع وظائف الدولة وتعدد

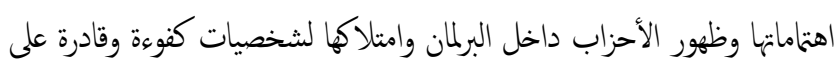

$$
\text { ادارة الدولة، وتخظى بثقة البرلمان }
$$

\subsubsection{2 دور رئس الدولة واختيار رئيس الحكومة}

ان لمبدأ ثنائية السلطة التنفيذية جانب شكلي حيث يتضمن على الفصل بين منصبي رئيس الدولة ورئيس الحكومة وعدم جمعها، وجانب موضوعي ويتمثل بمارسة اختصاصات السلطة التنفيذية الفعلية من قبل رئيس الحكومة55. وان دور
وعليه فرئيس الحكومة هو الذي يختار الوزراء الذين يساعدون معه بسلطة تقديرية

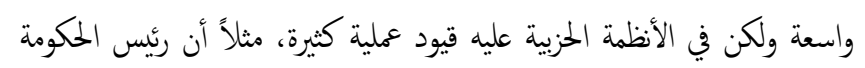
وهو عادة زعيم حزب الأغلبية يختار وزراءه من القيادات الحزبية وكثيراً ما يكون مرجع الإختيار للحزب نفسه لا لمض ارادته. فعند قيام رئيس الدولة بتعيين الوزراء في مناصبه فإن هذه الأداة وفقا لأسس النظام البرلماني تكون شكلياً مضضاً (44). فالأغلبية الحزبية في البرلمان يؤدي دوراً أساسياً في مسألة تحديد العلاقة بين رئس الحكومة والوزراء، بجيث اذا كان الحزب الذي يؤلف الحكومة لا يشكل الاّّ أغلبية بسيطة، فإن ذلك سوف يترك متسعاً من الحرية للحركة بالنسبة للوزراء، في مثل هذه الحالة يكون رئس الحكومة مجرد رئيس لمجلس الوزراء أكثر من كونه قائداً للسلطة التنفيذية اضافة الى الضعف الذي يعتري الحكومة في موابهة السلطة التشريعية(45). ووفقًا لمبادئ النظام البرلماني يجب أن يكون رئيس الحكومة والوزراء أعضاءً في البرلمان، ويذهب الدكتور ليلة اله أن ذلك ليس بالأمر الحتمي، بل يجب أن يتقرر ذلك في الدستور ، وفي مجلس الوزراء برئاسة رئيس الحكومة يتحقق الانسجام

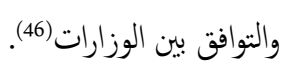
عمواً ان النصوص الدستورية لا يقوم بتحديد طبيعة العلاقة والسلطات التي تورتي يمارسها رئيس الحكومة على الوزراء، إلا أنه يككن استنباط وضع هذه العلاقة بين رئيس الحكومة الوزراء من خلال الدور الذي يقوم به عند تشكيل الوزارة وضرورة استمرارها في الحكم على أساس تحقق عناصر الوحدة والانسجام والتضامن، وهذه العناصر تتوقق إلى حد كير على شخصيته وصفاته، كتمتعه بالعلم والإدراك، والسعي لرسخ روح الشعور بالمسؤولية في زملائه، فرئس المكومة لا يملك حق عزل وزير معين دون الحصول على موافقة الرئيس او البرلمان لأنه من

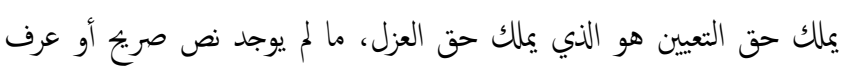

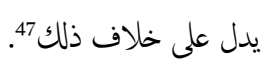
الأنظمة القانونية التي تحدد صلاحيات رئس الحكومة ومجلس الوزراء تكثف حالة العلاقات في بريطانيا بين القانون الدستوري كنصوص قائمة وبين عملية تطبيقها على أرض الواقع (48). لكن هناك نصوصاً تتولى تحديد هذه العلاقة في الدساتير المدونة، مثلاً في ألمانيا تتألف الحكومة الإتحادية من المستشار الإتحادي ومن الوزراء الإتحاديين، وان المستشار الاتحادي هو الذي يقرر الخطوط الإستشارية العريضة للسياسة ويتحمل مسؤوليتها. وكل وزير يدير وزارته بشكل مستقل ضمن حدود تلك الخطوط والتعلميات وعلى عاتق مسؤوليته (49). 


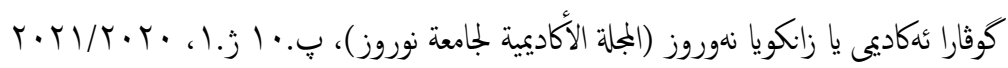

الذي يقوم باختيار الوزراء، وعليه ان يعرض أسماءهم على رئيس الدولة ليقر هذا الإختيار ، ويوافق على تأليف الوزارة، ويصدر أمره بذلك، وعندئذ يتم تعيين الوزارة بصفة رسمية16. وعليه، يتمع رئيس الدولة بقدر كاف من الحرية عند عدم وجود التنظيم الحزبي، وحرية اختياره تكون محدودة حين تتواجد احزاب متعددة، لأنه مجبر على اختيار رئيس الحكومة من بين أعضاء الأغلبية في البرلمان، وقد تنعدم حرية اختياره في حالة وجود حزبين في البرلمان، لأنه مضطر الى

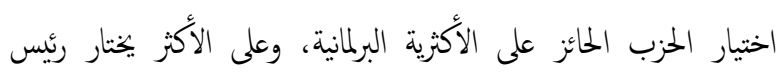

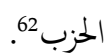

\subsubsection{2 دور البرلمان في اختيار رئيس الحكومة} دور البرلمان بصدد اختياره لرئيس الحكومة، اما يكون بالمشاركة بين رئيس الدولة والبرلمان أو يتم اختياره من قبل البرلمان لوحده فقط، ونبحث ذلك فيا يلي: الإختيار بالمشاركة بين رئس الدولة والبرملان: يقول بعض الفقهاء بان البرلمان هو الذي يقوم بتعيين الحكومة، والأخيرة ما هي الآّلجنة برلمانية ينتجها البرلمان للقيام بأعمال السلطة التنفيذية وأول من أورد هذه الفكرة هو الإنكليزي Bagehot في كنابه The British Constitution حيث قال بان اللجنة التنفيذية هي اكبر وأهم لجنة برلمانة، نعم ان البرلمان لا يختارهم مباشرة ولكن اختياره لهم بالواسطة لا يقلل من سلطة اختياره المطلقة،

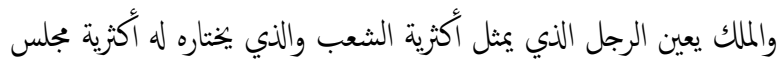
النواب، ومن حيث التعيين شبه بيجوت رئيس الحكومة الإنكليزي برئيس الولايات المتحدة، فكما ينتخب الأخير من الشعب على درجتين كذلك ريك رئيس الوزارة الإنجليزية يختاره عملياً مجلس العموم المنتخب بواسطة

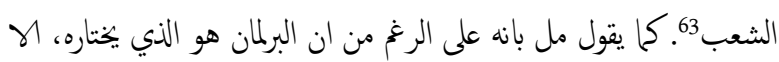
انه يجب أن يعين رسمياً، في نظام ملكي، من قبل التاج، والوزراء ينتخبون

$$
\text { بطبيعة الحال من جانب رئيسهم }
$$

ب- اختيار رئيس الحكومة من قبل البرلمان: هذا النوع قد تحقق في بعض لمض الدساتير البرلمانية الصادرة بعد الحرب العالمية الثانية، فنصت على تعيين

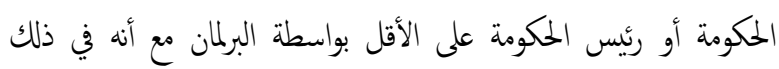
إضعاف كبير للسلطة التنفيذية ومسخ للنظام البرلمانئ. ويذهب جون ستيوارت مل الى انه من المستحسن ان يعين رئيس السلطة التنفيذية في النظام الجمهوري من قبل البرلمان كما يعين في الواقع رئس الوزارة في النظام
رئس الدولة يختلف في كون النظام البرلماني نظام مزدوج أم نظام فردي، ونبين ذلك وكلآتي: أ. في النظام البرلماني المزدوج (الثنائي) حيث يتقاسم السلطة التنفيذية بين رئيس الدولة ورئيس الحكومة، و يملك رئيس الدولة حق تعيين وعزل رئيس الحكومة والوزراء بجيث يصبحون مسؤولون أمام البرلمان وأمام رئيس الدولة، وصلاحية حل البرلمان يكون بيد رئيس الدولة، والحكومة مضطرة الى تقاسم السلطة عملياً مع رئيس الدولة (56.). وتم تطبيق هذا النظام في كل من فرنسا وكذلك في ألمانيا من عام 19191933 وفي المملكة المتحدة في الفترة من 1689 وحتى 1782 وكذلك في كل من مصر 57 والكويت وغيرها. أما هذا النوع من الصلاحية لرئيس الدولة في المسائل المتعلقة بشؤون الحكى في النظام البرلماني المزدوج يجب أن يقف عند حدودها وإلا تتغير الكيان الأساسي لهذا النظام ويبتعد عن الروح الحتيقية للنظام البرلماني (58). مثلا اذا كان الرئس من الناحية الدستورية حراً في اختيار رئس الحكومة، ولكن هذا الأخير ملزم بعرض حكومته على البرلمان، ولا بد من حصوله على موافقة هذا الأخير لتننيذ برنامجه، وتتوقف موافقة البرلمان على مدى سرى توافق برنامج الحكومة مع سياسة الحزب صاحب الأغلبية في البرلمان، وفي حالة عدم موافقته قد تؤدي اما الى استقالة الحكومة أو حل البرلمان، وقد ياتي انتخاب الجديد بنفس الأغلبية وبذلك يكون رئس الدولة في موقق لا يحسد عليه59. وفي النرويج يختار الملك بنفسه "جلس الدولة" من بين المواطنين النزوييين من يجق لم الإنتخاب، ويتألف "البملس" من رئس

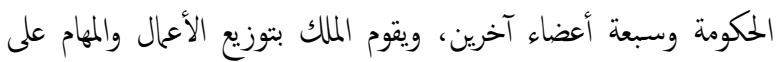
أعضاء المجلس، كما يراها مناسبة 60. ب. أما في النظام البرلماني الفردي فالمكومة تمارس السلطة الفعلة، ولا يملك رئس الدولة استقلالية اختيار رئس الحكومة وان كان هو الذي يعينه في الواقع ـ كونه ملتزم بتعيين زعيم الأغلبية في البرلمان، وليس له عزل رئيس الحكومة لأنه ولد من الإغلبية البرلمانية الآّاذا فقدت الوزارة ثقة البرلمان، وهذا النوع مطبق في كثير من البلاد الأوربية منها انجلترا وأسبانبا وأملانيا وإيطاليا...الخ. وفي هذ الإطار الدستوري يقوم رئيس الدولة باختيار رئيس الحكومة ثم يقوم بتكليفه بعد ذلك بتشكيل الحكومة، ورئيس الحكومة بعد اختياره هو 


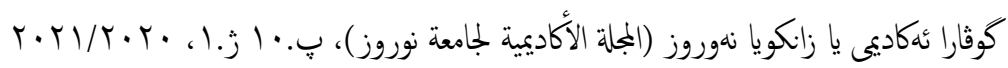

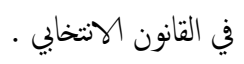

وعليه، ان لم يستطع الحزب الفائز في الإنتخابات ايجاد أكثرية مريحة لنيل ثقة البرلمان، ف (يختار رئيس الدولة زعيم الأغلبية البرمانية أو احد زعائها البارزين، وهو بدوره يقوم باختيار أعضاء الوزارة وعرضهم بعد ذلك على رئيس الدولة ليقر الإختيار ويصدر أمره بتعيين الوزارة) 99. ونزى بانه من حق الكنلة أو الحزب الفائز الإنتخابي الأول ان تعطى له الأولوية مرتين بتكليفه لتشكيل الحكومة اذا أمكن ان يحصل على ثقة الأغلبية البرلمانة، ولكن الأحزاب يجب عليها ان تتصرف بشكل قيادي ومسؤول في هذا الإطار ، بحيث اذا تبين بان أي حزب من هذه الأحزاب لا يستطعع القيام بذلك، فعليه ان يبدي رأيه مسبقا في ذلك، حتى يكون بالإمكان اختيار

ت- عدم وجود أغلبية واضحة ومتجانسة: التجانس الوزاري هو المبدأ الذي يجب أن يوجد تشكيل الحكومة070، أما في بعض الظروف الطارئة فان هذا المبدأ لا يظهر أحياناً وتتشكل وزارات غير متجانسة بحيث بقؤها محكوم ببقاء سبب وجودها 77. ومن أمثلنها حكومة الجمع بين الأحزاب المتقاربة وهي نوع من التشكيلة الوزارية التي تجمع بين الأحزاب المتقاربة في أفكارها وتوجهاتها وبرامجها (72). مثلاً الحكومة الإيتلافية وهي ائتلاف وزاري بين بعض الأحزاب القوية برغز ائنلاف برامجها، وهم مضطرين لذلك لعدم قدرة كل واحد منها الحصول على ثقة البرلمان منفرداً (73)، او حكومة وحدة وطنية حيث يظهر هذا النوع من الحكومات أثناء الأزمات القومية وفي اوقات ضرورية. ورغ أنه قد يكون لأحد الأحزاب تمثيل ما داخل البرلمان يسمح لل بتشكيل الوزارة بمفرده ال انه يرى ضرورة اشتراك الأخرين المؤثرين في الحكي7، او الحكومة الإدارية حين تتألف لفترة قصيرة لموابحة ظروف طارئة وتتسلم الحكومة المشكلة من حزب الأغلبية دفة الحكم مرة أخرى وغالباً ما تتألف من وزراء غير متحدين في سياستهم لفترة قصيرة(75). فاذا تعددت الأحزاب ولم توجد أغلبية برلمانية متجانسة، تقوم الرئيس بمارسة حقه في اختيار من يكلفه بتشكيل الوزارة في حرية (76). بعد اجراء استشارات يقوم بها لنكليف من يتولى رئاسة الحكومة. وبعد ذلك يقوم رئيس الحكومة المكلف بمفاوضات تشكيل الحكومة. وهذه الآلية قد تختلف ما بين الأظظمة البرلمانية الثنائية والأحادية. (77).
الملكي الدستوري من قبل الهيئة التمثيلية، والتبرير هو ان التعيين بهذه الطريقة يكون لشخص بارز، والحزب الذي تكون له الأكثرية في الإنتخابات كقاعدة عامة يعين زعيمه، أو احد رجاله الطليعة بين رجال الحزب6.6. وفي هذا الإطار نرى بان التنظيم الدستوري لهذه الحالات في كيفية اختيار رئيس الحكومة يجب أن يكون واضحاً ويتضمن الإجراءات والضوابط والمدة الدستورية

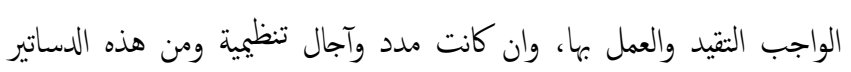
دستور دولة السويد.

\subsubsection{2 دور الأحزاب في تشكيل الحكومة}

في ظل النظام البرلماني، فان طبيعة النعددية الحزبية تلعب دوراً أساسياً في تحديد مسار اختيار رئيس الحكومة، ونبين ذلك وكالآتي:

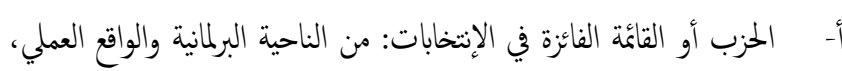
هو ان الشعب وحده يقوم باختيار الوزارة، فالحزب الفائز بالأغلبية الإنتخابية البرلمانية هو الذي يتولى رئاسة الوزراء وسيشكل الحكومة وذلك

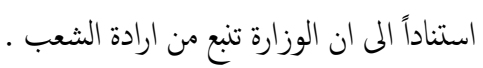
ويوجد هذه الصورة في الدول التي تعمد على نظام الأغلبية في قانونها الانتخابي، ويكون اختيار رئس الحكومة لحزب الفائز بالأكثرية الإنتخابية، لئ، ودور رئيس الدولة ياخذ الطابع الشكلي عند النكلف و التعيين. واعضاء الوزارة يتم اختيارهم من الحزب الحاصل على أغلبية الأصوات في البرلمان، و بمفهوم آخر أن اعضاء الوزارة يختارون من الشعب، وبالتالي فإن البرلمان يتضمن على أعضاء السلطنين التشريعية والتنفيذية في الوقت نفسه (67). وعند تحقق ذلك نكون امام خاصيتان أساسيتان وها(68):أن الوزارة تشكل من حزب الأغلبية داخل البرلمان مما يجعل الوزراء

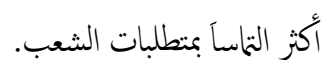
ان هذه الخاصية تتفق مع مبادئ الديمقراطية، لأن كل المؤسسات يجب أن تستمد وجودها عن طريق ارادة الشعب.

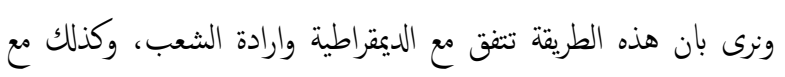
الواقع السياسي والتعدد الحزبي في اقليم كورستان. ب- الكتلة أو القائمة الأغلبية في البرلمان: هذا هو الشكل المعتمد حيث يوجد اكثر من حزبين، فيدخل احد الأحزاب في تحالف مع الأحزاب الأخرى لغرض نكوين الأكثرية ، كما هو حال أكثرية الدول التي تعتمد النظام النسبي 


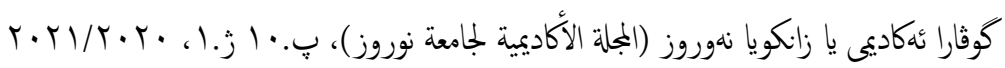

ج- حكومة التوافقية الحزبية: قد يوجد تمايز اجتاعي وانتسام سياسي يتمثل في وجود أقوام وأديان ومذاهب مختلفة تمثلها تشكيلات حزبية مختلفة، وهذه الأحزاب لا تحظى بتواجد وحضور مؤثز في كل مناطق الدولة، مما تصعب معه إمكانية تشكيل حكومة على اساس الأكثرية الإنتخابية أو البرلمانية، فن أجل دمج المكونات الأخرى لا بد من تشكيل حكومة تقوم على أساس

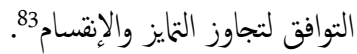
ح- حكومة الأقلية الحزبية: تتألف الحكومة من أعضاء الحزب الذين يمثلون الأغلبية في البرلمان، فإن الحزب الذي يفوز في الاتتخابات له أغلبية بفارق ضئيل مقارنة بالأحزاب الأخرى، واغلبية واسعة يلعب دور المعارضة كونم بعيدين من حيث الرؤى أو الإيديولوجية أو البرنامج الإنتخابي، لذلك قد

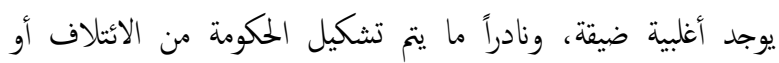
الأقليات ـ مثلاً، في نظام وستمنستر ، مثال على حكومة الأقلية كحكومة حزب العمال في عام 1974، فشل حزب العمل رغز حصوله على أكبر عدد من الأصوات في الانتخابات، في الحصول على أغلبية المقاعد في البرلمان. بعد ذلك ، وبدعز من الأحزاب التي لم تستطع أن تتحد ضده،

$$
\text { تمكن من تشكيل حكومة أقلية84. }
$$

وكذلك في عام 2016 سمح نواب الحزب الاشتراكي في البرلمان الإبباني بتشكيل حكومة أقلية، وقرر قادة الحزب الاشتراكي بأغلبية الأصوات خلال اجتاعهم في مدريد الامتناع عن حجب الثقة عند التصويت على حكومة الأقلية في مجلس النواب. وواجه البلد إمكانية إجراء انتخابات تشريعة للمرة الثالثة على التوالي في غضون سنة بسبب عدم حصول أي حزب على الأغلبية التي تنتح له تشكيل حكومة والحصول على الأصوات المطلوبة في مجلس النواب. وعند اصرار سكترير الحزب الاشتراكي بسبب إصراره على ججب الثقة عند عرض الحكومة اليمينية على التصويت فقد

$$
\text { قيادته للحزب }
$$

5.1.6.2 حالة الضرورة كتواعد متبعة لتجاوز الأسس المعمولة لأختيار رئس

الحكومة

الضرورات كقاعدة أصولية قانونية عامة وخصوصاً في حالة الأزمات أو الضيقة في إختيار البدائل، تتبع حالة الضروة لأختيار رئيس الحكومة. مثلاً في المملكة المتحدة يجب ان يتم اختيار رئيس الحكومة من سكرتير الحزب، حيث ان شخصية الشخص الرئيس في الحزب لتشكيل الحكومة محل نظر قانوني،
ث- وجود أغلبية برلمانية محدودة: اذا لم تؤدي الإنتخابات الى اعطاء ألأغلبية لأحد الأحزاب أو أدى الى أغلبية محدودة ومعروفة حيث نكون المقاعد البرلمانة موزعة بين أحزاب مختلفة ومتقاربة في القوة، فرئيس الدولة يتمتع

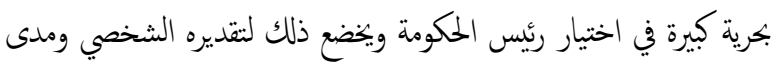
ثقته في الشخص الخختار بأنه سيعمل جاهداً وبيذل قصارى جمده في خدمة الدولة وفي الوقت ذاته يستطع بسياسته أن يكسب ثقة البرلمان ويحصل

$$
\text { على تأييده لسياسته (78). }
$$

فلرئيس الدولة استعال حق اختيار وتعيين رئيس الحكومة والوزراء بشيء من الحرية (ولو انه مقيد بقيود معينة) ولا يككن له ان يختارها بناء على كلى كرد سياسة شخصية بل وفقاً للصالح العام، وبشكل يتفق مع رغبة البلاد، ويستعمل هذا الحق باعتباره حكماً بين الأحزاب المختلفة، و ولا سيا اذا لم يكن هناك حزب قوي يضم اغلبية النواب، ففي هذه الحالة يكون أساس الإختيار هوتقدير رئس الدولة الشخصي لكفاية رئيس الوزارة ومقدرته على خدمة البلاد، واستطاعته في الوقت نضسه الحصول على تأييد البرلمان.79. وعليه، اذا جاءت الانتخابات بنتيجة غير واضحة، فقد يقوم الحزب الحائز على المرتبة الثالثة ومعه بقية الأحزاب بائتلاف مع الحزب الحائز على المرتبة الثانية، وليس مع الحزب الحائز على المرتبة الاولى في الانتخابات، فثنلاً في بريطانيا فان التقليد الدستوري لا يطبق، بل ان الملك يكون مخولاً دستورياً بدعوة قائد الحزب الحاصل على المرتبة الثانية ليشكل الحكومة (80). فئيس الدولة لا يتقيد باختيار زعيم الأغلبية مادامت لا توجد مثل لك تلاك الأغلبية لأي من الأحزاب، ولكن رئيس الدولة في الوقت ننسه لا يستطيع أن يختار شخصاً لا يخصل على ثقة البرلمان، واذا تم تعيينه فُصيره هو السقوط ليحل محله غيره من يستطبع أن يفوز بتلك الثقة (81). يكلف الدستور رئيس الدولة بأجراء المشاورات مع الأحزاب الفائزة في الدخول للبرلمان، لغرض تكليف احد قادتها لتشكيل الحكومة وضمان الحصول على ثقة البرلمان، وينص الكثير من الدساتير ذات النظم البرمانية على ذلك ، لان المعيار هو الحصول على الأغلبية داخل البرلمان وليس على الفايز الأول في الانتخابات، وهذا ما اعتمده الدستور الاسباني لسنة 1978 في والقانون الاساسي الألماني لسنة 1949.8. وبدورنا لا نتقق مع هذا الإتجاه الدستوري خصوصاً في الدول الناشئة من الناحية الديمقراطية. 


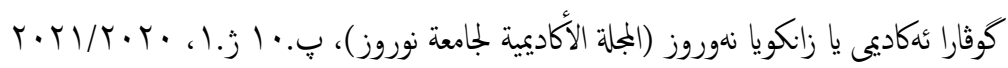

\subsubsection{3 اختيار رئيس المكومة في السويد}

يتشاور رئيس البرلمان مع مندوبين من كل بمموعة حزبية في البرلمان عندما تقتضي الضرورة لغرض تعيين رئس الحكومة، ويتداول مع نوابه أيضاً قبل عرض الأمر على البرلمان، ويجري التصويت في البرلمان في مدة أربعة أيام، وينتخب المرشح رئيساً للوزراء في حالة نيل الثقة على صوت أكثرية أعضاء البرلمان. وفي حالة رفض البرلمان أربع مرات يحل البرلمان عن طريق رئيسه وتجري انتخابات جديدة للبرملمان.

ويصدر رئس البرلمان كتاب تعيين رئيس الحكومة نيابة عن البرلمان 88. اذن يقوم الريكسداغ (البرلمان) بتسمية رئيس الحكومة، الذي يكلف بتشكيل الحكومة. ويقوم رئيس الحكومة شخصياً باختيار وزراء حكومته، ويقوم أيضاً بإسناد الحقائب الوزارية الخختلفة الى كل منه. ويشكل رئيس الحكومة سوية مع مجلس الوزراء الحكومة، وعادة ما يمثل الوزراء أحزاباً سياسية أو أحزاباً في السلطة. ويكون لم في حالات عديدة، مقعداً في البرلمان، يحتفظون به خلال فترة عملهم في مجلس الوزراء، بالرغ من وجود شخص بديل يتولى هام عضو الريكسداغ المعين في مجلس الوزراء. وعليه يجب أن يمتنع الوزير في الحكومة عن التصويت في البرلمان. ولكن يمق لممبع الوزراء المشاركة في المناقشات البرلمانية 89 اذا لا يوجد لرئيس دولة السويد (الملك) أي دور في كيفية اختيار رئيس الحكومة حتى من الناحية الشكلية، وليس للملك أي دور في اختيار رئيس الحكومة. 3.1.1.3 اختيار رئس المكومة في اليابان ان الدييت (البرلمان) في اليابان يقوم باختيار رئيس الحكومة من بين أعضاء البرلمان ويعين من قبل الأمبراطور، واذا اختلف مجلسا النواب والشيوخ على اختيار رئيس الحكومة، ولم يمكن الوصول الى اتفاق حتى بواسطة اللجنة المشتركة المجلسين التي نص عليها القانون، أو إذا فشل مجلس الشيوخ في إجراء الأختيار خلال عشرة أيام، تستثنى فهيا أيام العطلات، بعد توصل مجلس النواب الى اختيار، يصبح قرار مجلس النواب هو قرار البرلمان (90). ووفقاً للمادة 68 من الدستور الياباني يتولى رئيس الوزارء تعيين الوزراء، ويجب ترنب ترنب عليه مع هذا أن يختار أغلبية الوزراء من بين أعضاء البرلمان وبواسطة أعضاءه، واذا كان الإمبراطور يعين رئيس الحكومة الذي يختاره البرلمان، فانه مقيد بقرار البرلمان لأنه وبالتطبيق للمادة 7 من الدستور فان دور الأمبراطور يتتصر على التصديق على الأختيار، والتعيين الذي قام به رئيس الحكومة 91. ونظراً لإستمرار الحزب الديمراطي الحر في السلطة منذ تشكيله في تشرين الأول عام 1955 وحتى عام 1994، ثم دخوله في ائتلافات مع الأحزاب الأخرى لتنكيل الحكومة منذ
أما الضرورة قد تحول دون ذلك، كمالة ونستون تشرشل في الحرب العالمية الثانية حيث كلفه الملك بتشكيل الوزارة رغ انه لم يكن زعياً للحزب، وكذلك حالة عدم حصول المرشح لمنصب رئيس المكومة على الأغلبية البسيطة في المانيا، اذ يقوم رئس الدولة خلال سـبعة ايام امـا بتعيينه وإمـا بجل مجلس النواب وهي الحمالة الوحيدة التي يمارس الرئيس فيها سلطة حقيقية في اتخاذ قرار ما، وهو مرهون بالموقف السياسي المى حد كير.

\section{3. اختيار رئس الحكومة في الدول البرلمانية واشكالياتها في اقليم كوردستان- العراق}

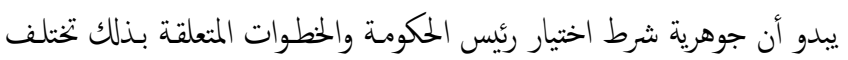
من دولة لأخرى، وان كان هناك بعض شروط وقواعد متفق عليه، ونتناول هذه

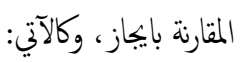
1.3 تحليل القواعد المتعلقة باختيار رئس الحكومة في الدول ذات النظام البرلماني المقارن واقليم كوردستان نختار في هذا المبحث كل من المانيا الإتحادية والسويد واليابان والعراق، كالنالي: 1.1.3 القواعد الدستورية لإختيار رئس الحكومة في الدول المقارنة فيما يلي نبحث باختصار اختيار رئيس الحكومة في كل من المانيا الإتحادية والسويد

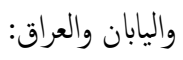

\subsubsection{3 اختيار رئيس الحكومة في ألمانيا الاتحادية}

رئس الجمهورية الاتحادية يقوم بانتخاب مستشار المانيا الاتحادية بناءً على اقتراح من قبل مجلس النواب (البندستاج) الاتحادي دون المشـاورة بأغلبية أعضاء المجلس، وعلى رئس المجهورية عندها تسمية (أعلان الفائز) في الانتخابات إذا لم يخصل المرشح على الاصوات اللازمة، فيجوز لمجلس النواب خلال 14 يوماً من الاقتراح الاول قبول غيره للمنصب، سواءكان مرشحاً من قبل رئاسة الدولة أو

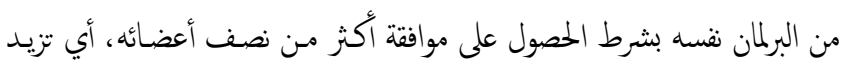
على نصف عدد أعضائه ليتم النعيين، وإلا كان واجباً اجراء اقتراع جديد وبلا تأخير يعلن فيه اختيار ذلك الشخص، الذي يحصل على الأغلبية البسبيطة، ويجب على رئيس الجمهورية أن يسميه مستشـاراً خلال مـدة أسبوع بعد جولة الأنتخاب، واذا لم يحصل المنتخب على هذه الأغليـة، فعلى رئيس الجمهورية الاتحادية خلال سبعة أيام أما أن يسميه مستشاراً أو أن يحل مجلس النواب الاتحادي (86). ويتم تسمية الوزراء الاتحاديين وإعفأهم من قبل رئيس الجمهورية الاتحادية بناءً على اقتراح المستشار الاتحادي(87). 


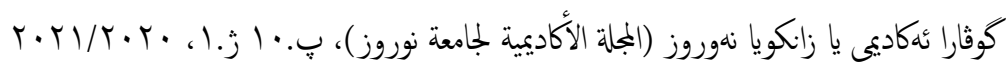

والمناجج الوزاري بالأغلبية المطلقة. وعند فشله يتولى رئيس الجمهورية نكلف مرشح آخر بتشكيل الوزارة (97). ان موضوع الكتلة النيابية الأكثر عدداً تم تفسيرها بموجب قرار المكمة الإتحادية ، والني بعد الرجوع الى آراء فقهاء القانون الدستوري ، توصلت المكمة الى ان (تطبيق أحكام المادة 76 من الدستور يأتي بعد انعقاد مجلس النواب بدورته الجديدة بناء على دعوة رئيس الجمهورية وفقًا لأحكام المادة 54 من الدستور ... وان الكتلة التي تكونت بعد الإنتخابات من خلال قائمة انتخابية واحدة، دخلت

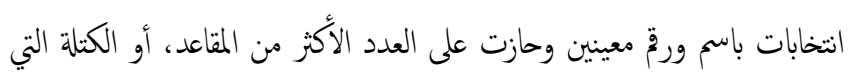
تجمعت من قائمينين أو أكثر من القوائم الإنتخابية التي دخلت الإنتخابات بأسهاء وأرقام مختلفة ثم تكنلت في كتلة واحدة ذات كيان واحد في مجلس النواب، أبها أكثز عدداً، فيتولى رئيس المههورية تكليف مرشح الكناة النيابية التي أصبحت

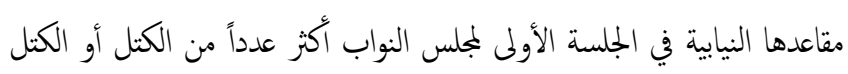
الأخرى بتشكيل مجلس الوزراء استناداً المى أحكام المادة 76 من الدستور) 98. وأتقق مع الباحثين الذين يرون بأن الإتجاه الأقرب والصحيح الى تفسير النص هو

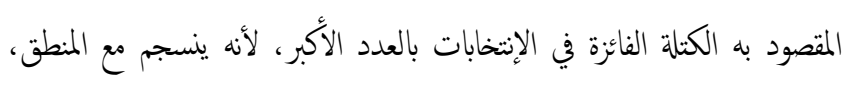
وبعكسه نتسائل لماذا يحدد بأن هناك كنلة حصلت أعلى الأصوات، وبذلك بلك يستلزم أن يكون لها إمتياز في تشكيل الحكومة، لذا فاننا نجد انه من الضروري

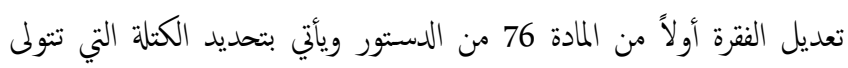
تشكيل الوزارة بشكل واضح دون التباس أو غموض الكتلة النيابية الفائزة في الأنتخابات، وبدورنا نؤيد الرأي القائل بانه (يكلف رئس المجمهورية مرشح قائمة الحزب أو الأيتلاف الحائز على أكثرية مقاعد مجلس النواب عند الإعلان عن نتائُ الإنتخابات، بتشكيل مجلس الوزارء)99. فاذا كان دور الشعب هو انتخاب أعضاء البرلمان وبيان دور الأحزاب من حيث أغلبيتها فان تكليف زعيم الحزب الحاصل على أغلبية الأصوات يكون تأييدا لرأي الشعب في اختيار شخصية معينة ليصبح رئيساً للحكومة 100.

ويعتبر العراق من الدول التي من الصعب أن تتشكل فها الوزارة على أساس

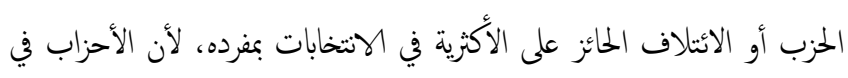
مجموعها هي أحزاب قومية ودينة منقسمة بين المكونات من بجة وكذلك فهي يؤدي الى تهميش وإقصاء أحزاب المكونات الأخرى من جحة ثانية لعدم امكنينها من سحب الثقة عن الحكومة التي تتشكل من مرشح حزب او ائنلاف المكون

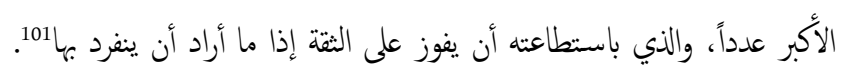

عام 1994، لذا يدعو جانب من الفقه بانتخاب رئيس الحكومة في انتخاب مباثر ، وان انتخاب المباشر من الشعب يتطلب تعديلاً دستورياً. وكذلك نص الدستور الياباني في الفقرة 2 من المادة 68 منه على أنه يجوز لرئيس الحكومة إعفاء الوزراء من مناصبهم حسب اختياره. وبهدف المشرع الدستوري من اعطاء رئيس الحكومة تلك السلطة لتمكينه من أن يحافظ على ترابط وانسجام اعضاء بجلس الوزراء، ويضمن بالتالي وحدة العمل الوزاري واتساقه سياسياً وادارياً ومن ناحية أخرى مراعاة تضامن الوزارة في شؤون الحكى والإدارة وفي المسؤولية السياسية. ويلاحظ أن مجلس الوزراء الياباني يصدر قراراته بالأججاع(93). ان جود بجلس الوزراء يعتمد فقط على ثقة بجلس النواب، إذا أقر مجلس النواب قرارًا بعدم الثقة في مجلس الوزراء، أو فقد الثقة به، فعلى مجلس الوزراء ان

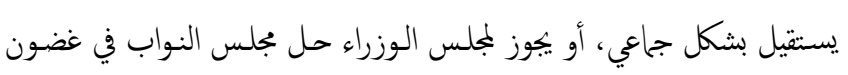
عشرة أيام ويدعو إلى إجراء انتخابات94. يجوز لمجلس الوزراء إما أن يستقيل

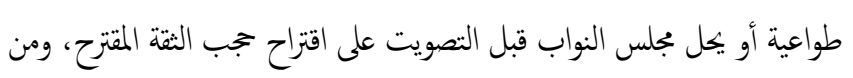

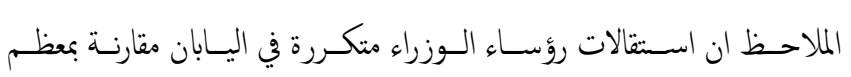

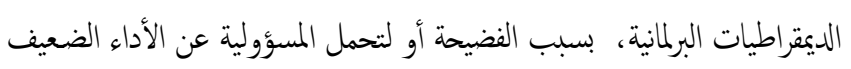
في الانتخابات، لكن الأكثر شيوعًا انهم قد استقالوا عند انتهاء فنزة ولايتهم كزعيم للحزب

\subsubsection{3 اختيار رئيس الحكومة في العراق}

لقد اشترط الدستور العراقي في رئيس الحكومة نس شروط الموجودة في رئيس الجمهورية، اضافة الى ضرورة حصوله على الشهادة الجامعية او ما يعادلها، وأتخ 35 من عمره ونص الدستور على تكليف رئس الجمهورية لرئس مجلس الوزراء فقط، دون التطرق الى الوزراء. حيث يكلف الرئيس مرشح الكتلة النيابية الأكثر عدداً بتشكيل مجلس الوزراء، وذلك خلال (15) يوماً من تأريخ انتخاب رئيس الجمهورية، ومن ثم يعرض رئيس مجلس الوزراء المكلف أسماء أعضاء وزارته والمنهاج الوزاري على مجلس النواب خلال مدة أقصاها ثلاثون يوماً من تأريخ التكليف، وعندعدم قدرة رئس مجلس الوزراء المكلف من القيام بذلك، يكلف رئس الجمهورية مرشحاً آخر خلال 15 يوماً، ويجب على المكلف الألزام بالمدة المنصوص عليها وهي ثلاثون يوماً. ويجب عرض اسهاء الوزراء والمناجه الوزاري على مجلس النواب، ويعد حائزاً على ثقتها، عند الموافقة على الوزراء منفردين، 


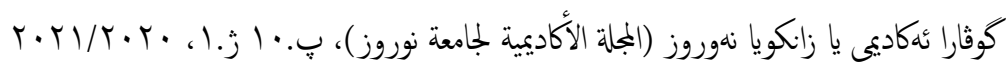

وبخلاف دساتير النظم البرلمانية لم يحدد دستور 2005 الجهة التي تصدر قرار

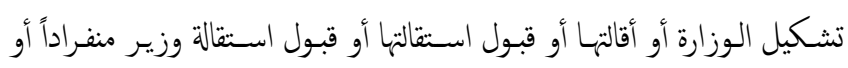
اقالته، وكذلك اقلة رئيس الحكومة وقبول استقالثه، وقد خالف الدستور بذلك سمة أساسية من سمات النظام البرلماني والتي تجعل ذلك مـ اختصاص رئيس الدولة ملـأكان أم رئيس جمهوريـة وإن كان الأمـر لا يتعدى الجانـب الشـكلي الإجرائي أسوة بالمراكز الوظيفية العليا في الدولة(104). ومن خلال التجرية التنفيذية

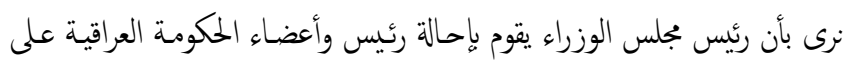
التقاعد دون سند قانوني، وكذلك رئس مجلس الوزراء هو الذي يقضي بتشكيل

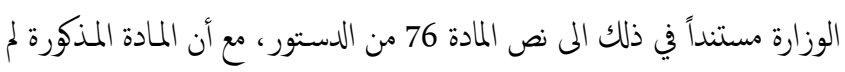
تخول رئيس الحكومة سلطة أصدار تشكيل الوزارة ولا احلة الوزراء على التقاعد، ومن المنطقي أن يقوم رئيس الجمهورية بإصدار هكذا مراسيم وذلك ونه هو رئيس الدولة والرئيس الأول في السلطة التنفيذية(105) وفي جمل مما بيناه اعلاه بصدد اختيار رئيس الحكومة، يجب ان ناخذ بالحسبان

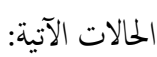

أولاً: ان قيام رئيس الدولة باختيار رئيس الحكومة هو واجب عليه وليس

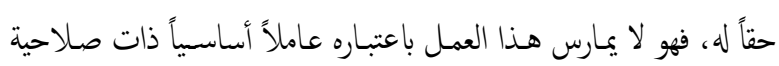
خاصة أي صاحب سياسة شخصية بل باعتباره حكما بين الأحزاب المختلفة، ولذلك فاذا كان دور رئيس الدولة في صدور تعيين الوزارة، لا يعدو ان يكون مجرد اقتراح وزراء وهو في هذا الأقتراح يتلمس رغبة البرلمان الذي له أن يرفض أو يوافق على تعيين رئيس الحكومة(106). ثانياً: تنحصر سلطة رئيس الدولة عندما تسفر الانتخابات عن عدم وجود أغلبية برلمانية واضحة في احد الاتجاهات التالية (107): - تكوين حكومة من الأقلية على أن يقوم بحل البرلمان عندما يتعذر عليها الحك. - تكوين حكومة من الأقلية تستطيع أن تبقى في الحكى، بتأييد من أحد

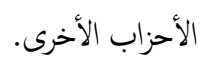

ثالثأ: ان العرف التقليدي في النظام البرلماني يجسد ترشيح رئيس الحزب

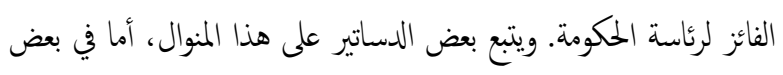
الدساتير الأخرى فتخول رئيس الدولة اختيار شخص آخر من الحزب
وهذا الإتجاه بدوره يرسخ التوافق والإنسجام بين المكونات الرئيسية من بهة، ولكنه يؤخذ عليه بأنه جلب المحاصصة الحزبية والطائفية للعراق بدلاً من أن يكون ائتلافات منسجمة لكي تكون أساساً لترسيخ الديمقراطية وخدمة الدولة من بجة

وفي حال اخفاق المكلف الأول بتشكيل الحكومة في مدتها الدستورية فيطرح مرشح ثاني بالإرادة المنفردة لرئيس المجهورية مستعملاً بسلطنه التقديرية لإختيار من يراه مناسباً لتشكيل الحكومة، وعند اخفاق الأخير فيقوم الرئيس بتقديره الشخصي بترشيح شخص آخر والذي يرى أنه بامكانه الحصول على الأكثرية المطلوبة. وبدورنا نرى بانه بما ان الكناة النيابية الأكثر عدداً ليس شرطاً أن يكون حائزاً على الأغلبية البرلمانية، والفقرة رابعاً من المادة 76 من الدستور العراقي تتطلب أغلبية

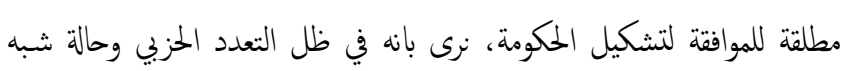
الإستحالة لنيل حزب ما على أكثرية مطلقة، فاما يعطى لرئيس الجمهورية حق

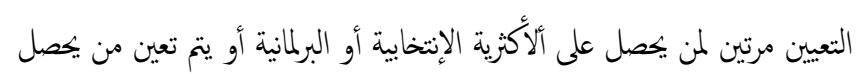
على الأكثرية في المرحلة الثالثة للتكليف رئيسا للوزراء أو حل البرلمان واجراء انتخابات جديدة. ولم يشر الدستور الى حالة استمرار البرلمان بعدم منح البرلمان الثقة بالحكومة لثلاث تشكيلات متتالية، ولكن الدساتير في النظام البرلماني وضعت جزاء للبرلمان وذلك بحله. فرئيس الدولة اما يسي الشخص الحائز على أكثرية بسيطة رئيسا للحكومة او يحل البرلمان ويجري انتخابات جديدة، أو يحل وديل البرلمان عن طريق رئس البرلمان كما هو الحال في السويد، أو يحل البرلمان بحل رئاسي. وفي الإطار الدستوري للعراق نرى بانه يمكن أن يطلب الرئيس من البرلمان حل نفس، أو ان رئس البرلمان يبادر بطلب حل البرلمان واجراء انتخابات جديدة. أما قرار النعيين بعد منح الثقة للوزارة من قبل مجلس النواب فلم يتطرق له النص ئس الدستوري، حيث انه لم يتعرض الى اصدار مرسوم قرار تعيين الوزارة أو إقالها أو قبول استقاتها أو استقالة أحد الوزراء أو إقالته. وان رئيس الجمهورية ليس له له أختصاص إصدار مرسوم بمهوري بتعيين الوزراء بعد حصولم على موافقة البرلمان بشكل منفرد، وقد أخذ هذا الدور رئيس مجلس الوزراء (102). أما لإقلة رئيس مئس مجلس الوزراء والوزراء، فقد منح الدستور لرئس الجمهورية الحت في طلب إقلاة رئس مجلس الوزراء، وهو يخضع لقرار موافقة مجلس النواب(103.) وعند طلب سحب الثقة من رئس مجلس الوزراء يكون المقصود من ذلك الوزارة مجمعة. 


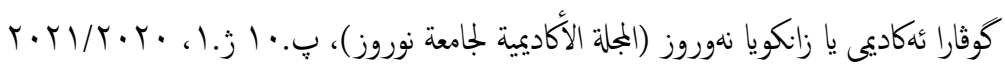

عدم وجود مجلس للوزراء حينها في هذا الوقت لكي يقوم بالتوقيع بجانبه

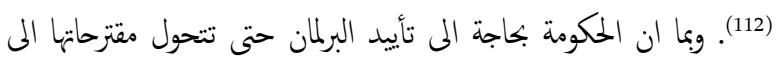
قوانين، فان التكوين السياسي للهيئة التنفيذية يصبح ذا أهمية كبيرة113 . سادساً: ان الموقف السياسي يلعب الدور الأساسي في اختيار رئس الحكومة، ويجب ان ياخذ رضاء الكنل البرلمانية ذات العدد الرئيسي بالأساس حتى في حالة الضرورة لإختيار رئيس المكومة او في حالة اطلاق يد رئيس الدولة للإختيار او للمفاوضات بين الأحزاب او عند عدم وجود أغلبية واضحة ومنسجمة في البرلمان. وهناك من يقول بان تشكيل الحكومة

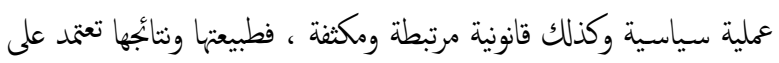
الظروف السياسية بقدر ما تعتمد على القواعد الدستورية المكتوبة (أو حتى غير المكتوبة)، سواء كانت هناك حاجة لإجراء انتخابات رسمية أو تنصيب شخص ما ، فن المتوق أن يكون رئيس الحكومة عادة هو زعيم الأغلبية في حزب الأغلبية أو الائتلاف في البرلمان 114

\section{3 اختيار رئيس المكومة في إقليم كوردستان} ان كيفية انتخاب رئيس الحكومة في إقليم كوردستان مرت بمنعطفات متباينة ومواقف متغيرة، هن الناحيتين التأريخية والقانونية لا نجد أسس ومعالم واضحة بصدد التعامل مع واحد من أهم الركائز والخصائص الأساسية للنظام البرلماني وهو موضوع رئيس الحكومة، بحيث تغيرت القوانين الدستورية من فترة المى أخرى بحكم الواق، فهناك ازدواجية في التسمية والترشيح والنكليف لرئيس الحكومة ونائبه وأحياناً مر القانون المتعلق بهذه المواضع في اطار غير دستوري، رغز كون البناء

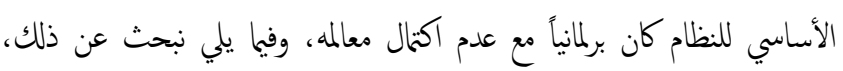

ان الرؤية الدستورية للسلطة المؤسسة لأصدار القوانين الأساسية في اقليم كوردستان بعد انتفاضة آذار المجيدة والمثثلة في الجبهة الكوردستانية لعام 1992، قد تمخت عن اقامة النظام البرلماني(115)، ولم تتطرق القيادة السياسية للجيهة الكوردستانية اللى كيفة تحديد العلاقة بين البرلمان والحكومة وكيفية بناء المؤسسات الرئيسة للنظام البرلماني (116). تسمية رئيس السلطة التنفيذية: استناداً الى قانون انتخاب البرلمان الذي أصدرته القيادة السياسية للجهة الكوردستانية، يمارس الجملس صلاحية تسمية رئس السلطة التنفيذية الذي له صلاحية تسمية أعضاء السلطة من

\section{لتكليفه برئاسة الوزراء.}

ففي بريطانيا يكلف الملك زعيم الحزب الفائز في الانخابات البرلمانية برئاسة الوزارة، إذ تجتع رئاسة الحزب الفائز ورئاسة الوزراء حكماً في ذات الشخص، وأي تغير يطرأ على رئاسة الحزب تقتضي بالضرورة تغيير رئيس الحكومة(108). ومثل هذا ما حدث عام 2007، حيث إنتخب حزب العال رئيساً جديداً للحزب أثناء ولاية رئس الحكومة توني بلير، الامر الذي أدى الى استقالة توني بلير عن رئاسة الحكومة في 2007/6/27، وتسمية وزير المالية في حكومته جوردون براون رئيساً للوزراء. وسلمت الملكة أليزابيت الثانية مقاليد السلطة اليه رسمياً وكلفته بتشكيل حكومة بريطانية جديد. وبعكس هذا الإتجاه الموجود في هذه الدساتير يخول بعض الدساتير الأخرى الرئيس صلاحية اختيار رئيس الحكومة، بغض النظر عن كونه رئيس أو مرشح الحزب الفائز في الانتخابات، وسواء إشترك في الانتخابات أح لا، وفي هذا الإطار يعطي قبول هذا الترشيح أو يرفضه. ومن بين الدساتير التي خولت الرئيس صلاحية مطلقة لاختيار رئيس الحكومة هي الدساتير الكويتية والقطرية، بحيث في الكويت يعين الأمير رئيس مجلس الوزراء، بعد المشاورات التقليدية، ويعفيه من منصبه، كما يعين الوزراء ويعفيهم من مناصبهم بناء على ترشيح من قبل رئيس مجلس الوزراء (109.) وفي دولة القطر يعين الأمير رئيس مجلس الوزراء ويقبل استقالته ويعفيه من منصبه بأمر أميري، وتشمل استقالة رئيس مجلس رد الوزراء أو اعفاه من منصبه جميع الوزراء، وفي حالة قبول الاستقلة أو الاعفاء من المنصب، تستمر الوزارة في تصريف العاجل من الأمور حتى يتم تعيين الوزارة الجديدة(110). وهناك دساتير تعطي للبرلمان حق التصويت لصالح هذا الاختيار من قبل الرئي، وبهذا الأتجاه ذهب دستور العراق ترست ومصر وفرنسا واليابان وماليزيا وغيرها من الدساتير. رابعاً: وهناك دساتير تعطي حق الرفض أو القبول البرلمان، بل قد يكون البرلمان هو الذي ييادر بالترشيح والتعيين عن طريق رئيسه. خامسأ: ان رئيس الدولة في النظام البرلماني له حق تعيين وعزل الوزراء وحتى حل المجلس حلاً رئاسياً، الو ان هذين الحقين مقيدان في الواقع بشروط مختلفة، ولا يكن استعالما بناء على سياسته الشخصية بل وفقاً للصالح العام وبما يتفق ورغبة الرأي العام في البلادد11. والسبب هو فانه 


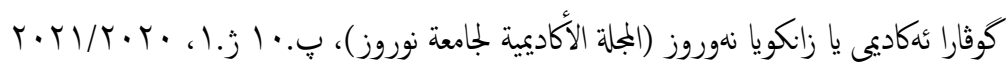

ليمنحهم ثقته (126). ولا نؤيد اتجاه ازدواجية المناصب بتكليف رئيس الحكومة ونائبة بنفس المستوى، لكونه يتعارض مع أسس النظام البرلماني.

ثالثأ: في الكابينة الثالثة: بموجب قرار برلمان كوردستان تم تسمية رئيس مجلس الوزراء(127)، وكذلك قام البرلمان بمنح الثقة لرئيس ونائب رئيس

$$
\text { وأعضاء مجلس وزراء الإقليم (128). }
$$

ولأول مرة تم إقرار المنهاج الوزاري لحكومة إقليم كوردستان في هذه الكابينة وألزم البرلمان مجلس الوزراء بتنفيذه(129). وقد استند البرلمان المى فقرة (4) من القانون رق (1) لسنة 1992 المتعلقة بمنح الثقة للسلطة التنفيذية، مع انه لا يوجد في هذا القانون مسألة موافقة البرلمان عدا المنهاج الوزاري أو الخطوط العامة منه، الآّ أنه ومن الناحية القانونية يجب أن تستند الإقرار الى قانون مجلس الوزراء(130.) ونحن نرى بأنه في الكلبينات الثلاث لمجلس الوزراء، ومع خلو منصب القائد وممارسة صلاحياته من قبل رئيس البرلمان، كان يجب على رئيس البرلمان والبرلمان وبعد التسمية أن يستندوا الى المواد المنصوص عليها في القانون رخ 2 لسنة 1992 فيه يتعلق باصدار القرارات المتعلقة بتكليف وتشكيل واستقالة الحكومة (رئيس ونائب رئيس واعضاء مجلس الوزراء)، الى حين إلغاء القانون رقٌ 2 لسنة 1992 أو ايقاف العمل به أو الى أن يحل محله قانون آخر لأداء وممارسة مثل هذا الصلاحيات

$$
\text { القانونية (131). }
$$

رابعاً: في الكابينة الرابعة: بعد اصدار القانون رقّ 10 لسنة 1997 (132)، اخذ التسلسل القانوني لكيفية التعامل مع الحكومة من حيث التسمية والتكليف والتشكيل وقبول الأستقالة مجراها الطبيعي في نظام الحكى في الإقليم الى حدِما، لأن هذا القنانون منح صلاحية القائد الى رئس البرلمان ورئيس الحكومة بخصوص بدء العمل بالإجراءات القانونية مع رئيس الحكومة والوزراء وكذلك صلاحية الدعوة الى إجراء الإنتخابات. نص الفقرتان (2، 3) من المادة الثانية من قانون رق 10 لسنة 1997 على

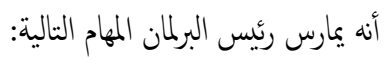
- - -
بين أعضاء البرلمان أو غير هـ (117). وبعد تسميته يصدر مرسوم من قبل قائد الحركة التحريرية الكوردية بتكليف من يسميه البرلمان لتشكيل السلطة النفيذية (118)،

\subsection{3 الكابينات الوزارية في اقليم كوردستان} بناء على ما سبق، ان اختصاص رئيس الدولة لأختيار رئيس الحكومة مقيد بوجوب اختيار زعاء الأغلبية حتى تحصل الحكومة على ثقة البرلمان، وهذا يعد مبداً اساسيا، وان الوزراء هم زعاء هذه الأغلبية لا أتباعها. وفقا للأسس القانونية والأصولية العرفية للنظام البرلماني كما بحثنا فيها نبين الوضع القانوني لرئيس الحكومة والقواعد المتبعة لإختياره واشكلياته القانونية في إقليم

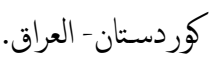
أولاً: في الكابينة الاولى: بسبب عدم فوز أحد من المرشهين لمنصب قائد الحركة التحررية الكوردية (119)، صدر أمر تعيين رئيس الحكومة ونائبه والوزراء من قبل رئس البرلمان (120) وذلك استناداً وتنفيذاً لمنطوق المادة 14 من قانون قائد الحركة التحريرية الكوردية رقّ 2 لسنة 1992 حيث جاء فيه: اذا خلا منصب القائد لأي سبب كان يقوم بهامه رئيس برلمان كوردستان لحين انتحاب قائد جديد خلال مدة شهر من خلوه (121. ولكن لم يرشح القائد حتى تطبق عليه نظام الخلو من عدمه. ثانياً: في الكابنة الثانية: رغز انه لا يوجد قرار سحب الثقة من الكابينة الأولى أو قبول استقالهه (122)، فقد أصدر البرلمان قراراً بتسمية شخص آخر رئيساً لمجلس الوزراء وتسمية نائبًا لرئيس مجلس الوزراء (123) و نحن لانجد أي سند قانوني لتسمية الرئيس ونائبه في هذه الكلبينة. اصدر البرلمان قراره بمنح الثقة لوزارة اقليم كوردستان العراق الثانية، ونحن لم لا نجد أمر النعيبن، بل اكتفى بجق منح الثقة فقط (124). ومن الملفت للنظر، ان البرلمان عقد جلسة خاصة لاستعراض ومناقشة مـذكرة استقالة حكومـة اقليم كوردستان وقرر قبـول استقالنها، وكلف أعضاءها بالإسيتمرار في تأدية المهام الإدارية لحين تشكيل مجلس وزراء جديد للأقليم(125). وبعد ذلك لا نجد قرار عزلم أو احاتهم الى التقاعد. وتم تسمية رئيس الحكومة ونائبه من قبل البرلمان وتم تكليفهم بتشكيل وزارة اقليم وتقديم مرشين للمناصب الوزارية المى برلمان في أقرب فرصة 


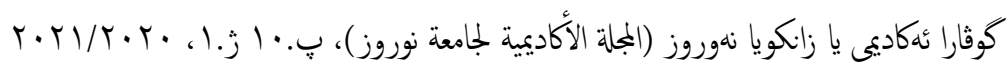

فيه مثلما كان عليه القانون من الأصل، حيث تم تسمية وتكليف رئيس

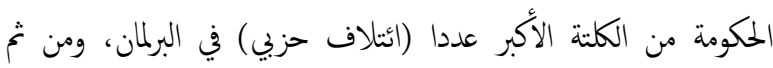

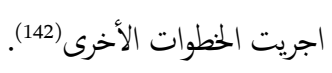

ثامنأ: في الكابنة الوزارية التاسعة: تم تسمية رئيس الحكومة من قبل برلمان كوردستان، بعد ترشيحه من قبل الأكثرية الإئتلافية داخل البرلمان 143، وتم تكليفه من قبل رئيس الإقليمب14، وتم منح الثقة بالحكومة من قبل البرلمان

$$
\text { وأصدر القرار بتوقيع نائب رئيس البرلمان.145. }
$$

ثاسعاً: كيفية اختيار رئس الحكومة في مشروع دستور اقليم كوردستان ان رئيس الإقليم يياشر اختصاصاً شكلياً بتكليف مرشح الكلتة البرلمانة الأكثر عدداً بتشكيل الوزارة (146)، وكما بينا سابقاً فنحن بدورنا ننتقد هذا الأتجاه ونرى بأن الحزب أو القائمة الفائزة في الانتخابات النيابية لها حق الأولوية بتكليف مرشحه لتشكيل الوزارة. وذهب المشروع الى تحديد مدة خمسة وأربعين يوماً لتشكيل الوزارة ونرى نخن بأن مدة 30 يوماً تكون مدة

$$
\text { مقبولة ومعقولة لإداء هذه المهمة. }
$$

وفي حالة اخفاقه يكلف مرشح آخر من نس الكتلة الأكثر عدداً في البرلمان ولملمدة ذاتها، ونخن بدورنا نؤيد هذا الإتجاه لكن في الكتلة الإنتخابية الفائزة في الإنتخابات، وعند اخفاق المرشح الثاني في تشكيل الوزارة، فلرئيس الإقليم سلطة تقديرية في اختيار من براه مناسباً وتكليفه بتشكيل الوزارة من أعضاء البرلمان أو غير همب. ونرى بأن مشروع الدستور من هذا الجانب اتجه اتجاها دقيقا ومقبولاً بتكليف الشخص الثاني من ننس الكناة في حالة اخفاق الأول، فيكون من العدل أيضاً أن يكلف المرشح في الحزب الفائز الثاني في المرحلة الثالثة أيضاً، وعند اخفاقه نكون أمام التقدير الشخصي لرئيس الإقليم. ( وذلك تجسيداً لدور الرئيس في النظام البرلماني حيث يلعب دوراً معتدلاً وتصالحياً بين السلطات وبين الأحزاب السياسية)148. ومبوجب المشروع فان البرلمان يمنح الثقة للحكومة(149)، وبعد ذلك يصدر رئس الإقليم مرسوماً بتشكيل الحكومة (150)، وكذلك لكن عند الأقالة والإستقالة (الوزارة أو الوزير ) يصدر مرسوم اقليمي كل انسجاماً

مع موقعه القانوني والدستوري(151).
الثالثة (133)، وتمت تسمية رئيس لمجلس الوزراء(134)، وقد منح الثقة للكلبينة الرابعة (135)، واصدر قرار تشكيل السلطة التنفيذية في الإقليم (مجلس وزراء إقليم كوردستان العراق)(136). وقد جمع البرلمان مسألة التسمية والترشيح والنكليف في نس الشخص وهو السيد رئيس البرلمان، ومقارنة بالنظام التي يتم تكليف رئيس الحكومة لا يوجد مثل هكذا الإجراءات المتكررة، وفي رأينا لا يوجد ضرورة قانونية وعرفية وسياسية لذلك. خامسأ: في الكابينة المامسة: بعد التغييرات والتحولات التي جرت في إقليم كوردستان والعراق، بدأت الخطوات الأساسية نخو إرساء وانشاء المؤسسات الدستورية في الإقليم خصوصاً بعد صدور الدستور المؤقت (قانون ادارة الدولة للمرحلة الإنتقالية) والثفكير بعجلة توحيد الإدارة، أصدر برلمان إقليم كوردستان قانون رئاسة اقليم كوردستان لعام 2005، وجاء فيه بأنه لرئيس الإقليم صلاحية تكليف رئيس الحكومة بعد تسميته من قبل

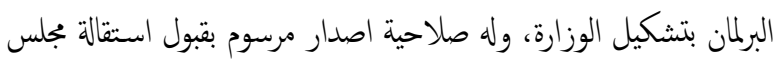
الوزراء أو الوزير عند سحب الثقة من أي منها، ولم يتطرق القانون الى أمر

$$
\text { تشكيل أو عزلم (137). }
$$

لكنه وفي عام 2006 جرى التعديل الأول على قانون رئاسة الإقلي، وعدلت فيها الفقرة 12 من المادة 10 من القانون وموجبه تتم تسمية رئيس الحكومة ونائبه من قبل البرلمان وكذلك يتم تكليفها معاً بتشكيل الوزارة 1388). وهكذا تمت تسمية كل من رئيس الحكومة ونائبه من قبل برلمان كوردستان، وتم تكليفها من قبل رئيس الإقليم لتشكيل الكابينة الخامسة ومنح الثقة بالوزارة كاملة من قبل برلمان كوردستان (139). ويثار المسألة حول تسمية رئيس الحكومة ونائه بنفس الصيغة والرؤية القانونية التي ورد في قانون الأنتخابات لبرلمان الإلقليم كما ذكناها سابقاً. سادسأ: في الكابنة الوزارية السادسة والسابعة: تم تسمية وتشكيل ومنح الثقة الكلبينة الوزارية السادسة على نس المنوال ووفق الأسس التي اعتمدت عليها لتشكيل الكلبينة الوزارية الخامسة (140). وكذلك تم تشكيل الكابينة الوزارية السابعة وفق نفس القواعد(141). سابعاً: الكلابينة الوزارية الثامنة: مع بداية الدورة الانتخابية الرابعة جرى تعديل على كيفية اجراء التسمية وتكليف رئيس الحكومة ونائبه مرة أخرى، حيث تم تعديل قانون رئاسة الإقليم، وبموجبه الني التعديل الأول، ودون 


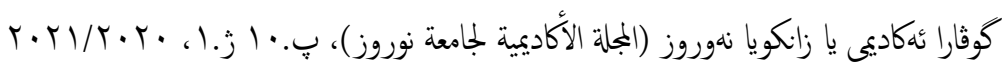

ب- عند عدم حصول أي حزب على الأكثرية العامة في الإنخابات، فان تشكيل الحكومة قد تنطوي على مفاوضات بين الأحزاب السياسية ثمهيداً لتشكيل حكومة ائتلافية تتمتع بثقة البرلمان، وقد تؤدي نتائج هذه المفاوضات الى توقيع اتفاق ائنلاف رسمي يحدد جدول أعمال السياسة العامة الذي يتحد الإئتلاف عليه. يككن أن نفكر في تشكيل حكومة أقلية، (حكومة تتسامح أو تتغاضى عنها غالبية أعضاء البرلمان، لكن تدع بصورة نشطة من قبل الأقلية فقط)، وقد يخظى هذا بدع رسمي من واحد أو أكثر من الأطراف الأخرى التي توافق على دع المكومة في التصويت على الثقة وفي الموافقة على الموازنة مقابل تنازلات تفاوضية في مجال السياسة العامة وذلك يسمى باتفاقية الثقة والتزويد أو الإعتاد دون الدخول الى تحالف كامل. وفي حالة عدم الوصول الى تشكيل الحكومة، فنتجه المى حل البرلمان واجراء

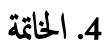
بعد أن انتيينا من موضوع البحث ، نركز في هذه الخائمة على أبرز ما توصلنا إليه وما نراه من توصيات، وذلك على النحو التالي:

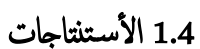

ان اختيار رئيس الحكومة في الأظمة البرلمانية قد يكون بشكل مباشر من الشعب أو بشكل غير مباشر من قبل رئس الدولة أو من خلال البرلمان. في الكثير من النظم البرلمانية لرئيس الدولة حق أختيار رئيس الحكومة وقد يكون له حق تعين وعزل الوزراء.

رئيس الدولة محكوم باختيار رئيس الحكومة من حزب الأغلبية البرلمانية في الأظمة البرلمانية بشكل عام، ولكن توجد أسس مختلفة لأختيار رئيس الحكومة اذا فاز في الانتخابات أحزاب متعددة ولم يكن هناك حزب ذات أغلبية برلمانية واضحة. دور الأحزاب يعتبر مؤثراً على التوازن والثبات والإستقرار والإسيتمرار في الحكومة البرلمانية حيث ان كل ذلك يعتمد على ضضج الأحزاب في تشكيل الحكومة من الناحية السياسية والقانونية وتحمل المسؤلية . يعهد المى رئس الحكومة باختيار الوزراء، والوزراء يككن أن يختاروا من

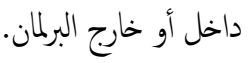

\subsection{3 الإثكاليات الواردة في قوانين اقليم كوردستان} بقدر ما يفيد بكثنا، فيما يلي موجز للأشكياليات المتعلقة باختيار رئيس الحكومة

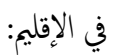
أ. لا يستند ترشيح رئيس الحكومة أو تكليفه الى الكتلة الفائزة الأولى في الإنخابات النيابية. وكذلك وقع مشروع الدستور في معضلة الكناة النيابية الأكثر عدداً كما ورد في الدستور العراقي، ونخن بدورنا ندعو المى تصحيح هذه المسألة وذلك حاية لرأي الناخب وتجسيداً لإرادة العامة وكذلك لكسب الثقة سياسية وتاسيس بنية وعملية سياسية راسخة وديمقراطية متينة ومقبولة للجميع بعيدا عن الإيتلافات الغير المجدية مؤدية الى الإنسجام في البرامج الإنتخابية وغيرها. ب. لا توجد هناك شروط في القانون التي يجب ان تكون متوافرة في شخص رئيس الحكومة وكذلك بالنسبة للمرشين للوزارات أيضاً. ج. نجد تغيير شبه دائم في الأحكام المتعلقة بتسمية رئيس المكومة ونائبه ايضاً وعدم ثباتها. د. وفق مشروع دستور الإقليم، للمرة الثانية يكلف شخص ثاني من نفس بـ الكناة لتشكيل الحكومة وهذا يعد أمراً مقبولاً، فن العدل ان يكون المكلف مرشحاً من الكتلة الفائزة الثانية في الإنتخابات في المرحلة الثالثة. هـ. هناك دوامة غير مجدية وعلى نفس الأسس في كيفية اختيار رئيس الحكومة وتشكيل الوزارة رغ التباين الواضح في عدد أعضاء الأحزاب المختلفة في

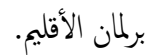
و. هناك مفاوضات وحوارات قد تطول الى ما يقارب ثمانية أشهر بل أكثر لتنكيل كابينة جديدة، وهذا يدل على ضعف القواعد الدستورية والإعتاد على عرف فاسد في هذا الإطار التي لايرغب بها الرأي العام ولا يتطابق مع مصلحة الشعب.

3.2.3 الأسس التي ييب أن تؤخذ بنظر الإعتبار عند عملية تشكيل الحكومة152: هناك قواعد متابنة في النظام البرلماني التي توضع لإختيار رئيس الحكومة وتشكيل الكابينة الوزارية، بدورنا نؤيد الأسس الآتية:

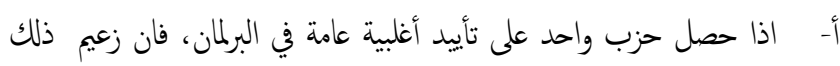
الحزب عادة سيكون لديه حق المطالبة المشروعة ليتم ترشيحه كئيس للحكومة، والحكومة تكون حكومة الأغلبية في البرلمان، وفي هذه الحالة قد تكون عملية تشكيل الحكومة مجرد إجراء شكلي يأخذ أياما محدودة. 
مع مصاح الإقليم والتوقيتات الدستورية المتعلقة بذلك، لنا نتزح ان تقلل

$$
\text { المهلة المى ما بين } 10 \text { - } 15 \text { يوماً. }
$$

أن تكون القوانين الدستورية مصونة بعيدة عن التعديلات الوقتية، ونؤيد اصدار قانون خاص بتشكيل الحكومة في اقليم كوردستان أو تعديل القوانين الختصة بذلك وبأتجاه سليم لتشكيل الحكومة في النظام البرلماني. من الضروري مراجعة قانون انتخاب برلمان الإقليم بما يتاشى مع تحقيق

$$
\text { المقومات الأساسية للنظام البرلماني. }
$$

ان مشروع دستور اقليم كوردستان والقوانين الموجودة الختصة بتأليف الحكومة جاءت على صيغة السائدة في الإقليم وذلك بحاجة المى الوقوف عليه بصدد تشكيل المكومة، وتصحيحه مستقبلاً عند كتابة الدستور في إقليم

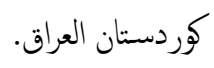

من الأفضل للنظام البرلماني في العراق واقليم كوردستان أن يكون بعض

$$
\text { الوزراء السياسيين من أعضاء البرلمان }
$$

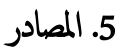

\section{5}

1. ابراهيم عبدالعرزيز شيها، النظم السياسية والقانون الدستوري، منشأة المعارف

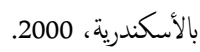

2إلمر بيشك، حكومة المانيا المعاصرة، ترجمة محمد حتي، مكنبة الأنجلو المصرية، القاهرة،

.1973

3. أنور مصطنى الأهواني، رئيس الدولة في النظام الديعراطي، رسالة دكتورا مقدمة كلية الحقوق بجامعة فؤاد الأول، مطبعة حجازي بالقاهرة، 1945.

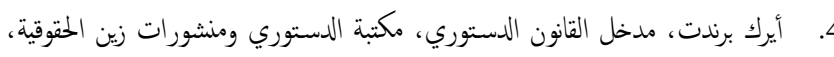

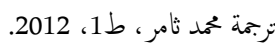
5. جون ستيوارت مل، الحكومات البرلمانة، ترجمة أميل الفوري، دار اليقظة العربية للتأليف والترجمة والنشر، 1958. 6. د. ابراهيم درويش، النظام السياسي، دراسة فلسفية تحليلة، دار النضضة العربية،

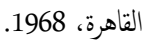
د. دابراهيم عبدالعزيز شيحا، النظم السياسية الدول والحكومات، دار النهة العربية

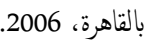
8. دـ ابراهيم عبدالعزيز شيها، وضع السلطة التنفيذية رئس الدولة والوزارة في الأظمة

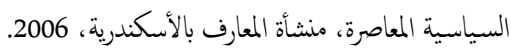

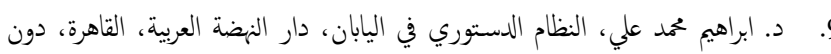
10. د. أحمد خورشيد حميدي، السلطة التنفيذية بموجب الدستور العراقي، مجلة جامعة

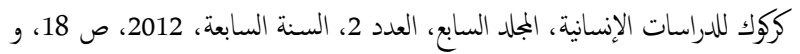

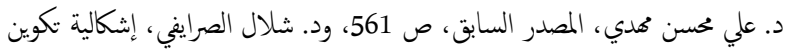

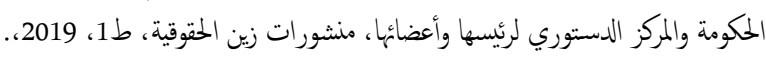

يلعب البرلمان دوراً رئسياً وأساسياً لمنح الثقة لرئس الحكومة وأعضاءه ومنهاجه الوزاري.

لانجد قواعد واضحة وراسخة لكيفة إختيار رئيس الحكومة والجهة التي تقوم باصدار أمر التعيين أو عزل رئيس ونائب وأعضاء ججلس الوزراء أو احاتهم الى التقاعد في القوانين الدستورية في اقليم كوردستان. لايوجد خط مستقيم لكيفة تسمية رئيس الحكومة من قبل البرلمان وتكليفه

$$
\text { بتشكيل الحكومة في اقليم كوردستان. }
$$

يككن أن يكون الإنتخاب المباشر لرئيس الحكومة أحد الخيارات الأساسية

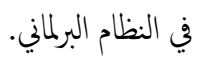

2.4 التوصيات

يجب أن ينص الدستور او القانون وبصورة واضحة ودون لبس او غموض على أن يكون للحزب أو القائة الفائزة الأولى في الانتخابات حق تكليفه لتقديم مرشحه لتشكيل الحكومة في النظام البرلماني لكوردستان العراق وذلك للإبتعاد عن الإجتهادات الخاطئة وغير المجدية التي تذهب بتاخير

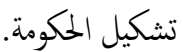

من المستحسن أن يخظى الحزب الفائز الأول في الانتخابات لتكليف مرشحه بتشكيل الحكومة لمرتين ، وفي حالة كجزه، يعطى الفرصة للحزب الفائز الثاني، وبعد ذلك يجب ان يكون لرئيس الإقليم السلطة التقديرية بتكليف من يرى فيه القدرة والإمكانية على نيل ثقة البرلمان. الغاء مسألة تسمية المرشح من قبل البرلمان لأن الفائز الأول الإنتخابي يكسب هذا الحق بمجرد المصادقة على نتائج الانتخابات. يمنح صلاحية اختيار الوزراء للمكلف بتشكيل الحكومة بعيدا عن الإعتبارات السياسية. أن يمنح صلاحية تعيين رئيس الحكومة ونائبه والوزراء وكذلك احاتهم الى التقاعد الى رئيس الاقليم حصراً. الغاء قانون رقّ 1 لسنة 2014، وان تعدل الفقرة 12 من اصل قانون رڤ 1 لسنة 2005 المعدل بما ينسجم مع الحلول المقترحة في هذا البحث. ان فترة 30 يوما وفقا لقانون رئيس الإقليم و45 يوما وفق مشروع الدستور التي منحت للمكلف بتشكيل الحكومة فترة طوية جداً، وتتعارض 


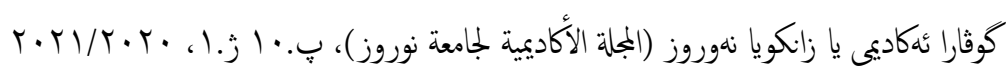

36. د.محمد كمل ليلة، النظم السياسية الدولة والحكومة، دار النضة العربية، ببروت،

.1969

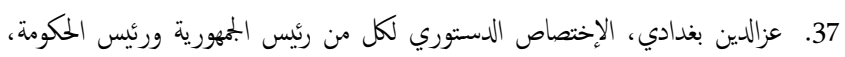

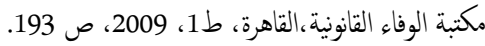

38. عوض الميون، المركز الدستوري لرئيس المكومة في النظام الدستوري الأردني، بجلة

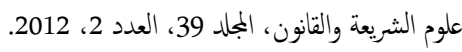

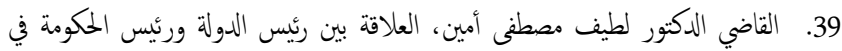
النظام البرلماني، دار سردم الطباعة والنشر، ،السليانية، 2009.

40. موريس دوفرجية، المؤسسات السياسية والقانون الدستوري والأنظمة السياسية

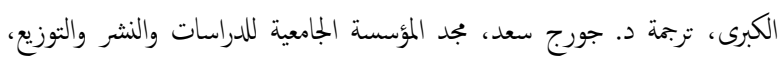

1992،16

\section{5}

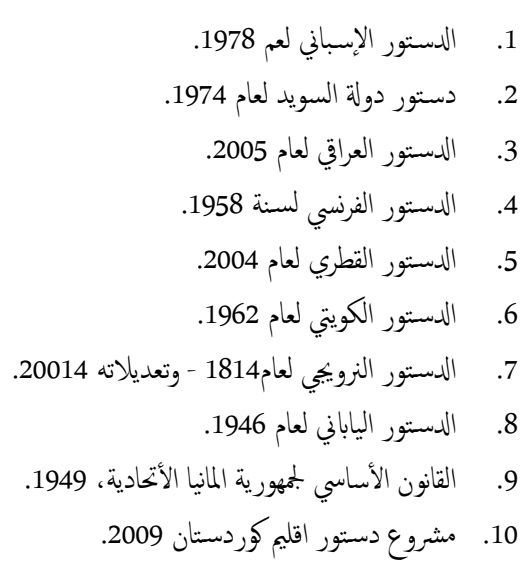

3.5

1. قانون انتخاب برلمان كوردستان العراق رڤٌ 1 لسنة 1992 المعدل، طبعة ايلول، .2016

2.

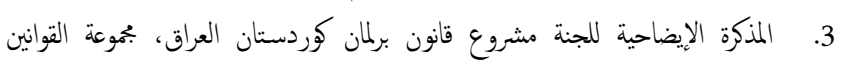

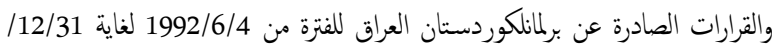

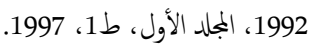

4. 5.

6. 7.

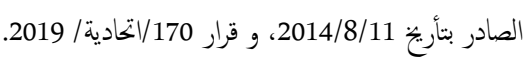

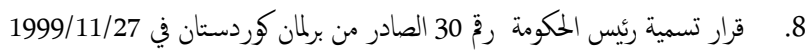

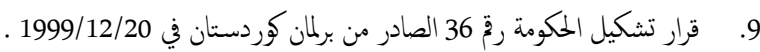

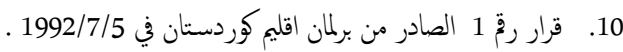

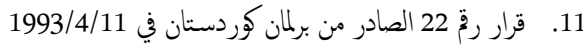

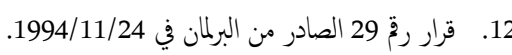

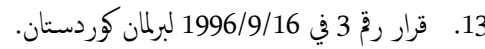

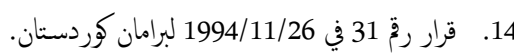

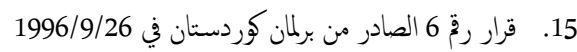

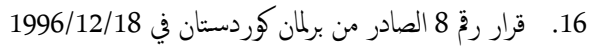

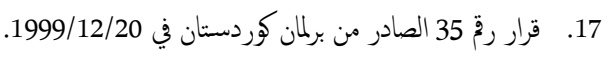

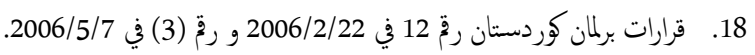

11. د. أمد سلامة بدر، الاختصاص التشريعي لرئيس الدولة في النظام البرلماني، دار النهضة العربية، القاهرة، 2003.

12. د. أمد عبداللطيف ابراهي السيد، دور رئيس الدولة في النظام السياسي الديمقراطي

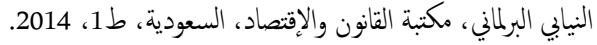

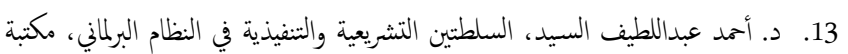
القانون والإقتصاد، السعودية - رياض، دئس 14. د. السيد صبري، مباديء القانون الدستوري، ط4، القاهرة، 1949.

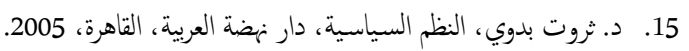

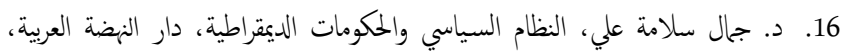
ط 2007 . 200

17. د. حازم صادق، سلطة رئيس الدولة بين النظامين البرلماني والرئاسي، الهيئة المصرية

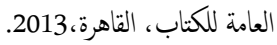

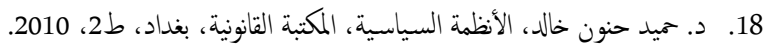

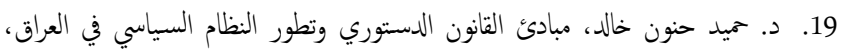
مكتبة السنهوري، بغداد، 2012.

20. د. حيدر المولي، التضامن الوزاري والحكومات الأيتلافية، منشورات زين الحقوقية، ط $2011 ،$

21. د. عبدالميد متولي، القانون الدستوري والأظمة السياسية، منشأة المعارف

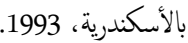

22. د. عصام سليمان، الأنظمة البرلمانية بين النظرية والتطبيق، منشورات الحلبي الحقوقية، بلنة ط

23. د. علي مجيد العكيلي، الحدود الدستورية للسلطة التنفيذية في الدساتير المعاصرة، المركز

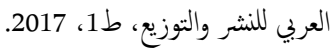

24. د. فتحي فكري، جواز الجمع بين العضوية البرلمانية والوظائف والأنشطة الأخرى، دار النهضة العربية، 1994.

25. د. فؤاد العطار، النظم السياسية والقانون الدستوري، دار النهضة العربية، ط2، .1973

26. د. ماجد راغب الحلو، النظم السياسية، دار الجامعة الجديدة، 2007.

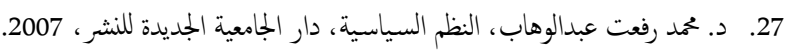

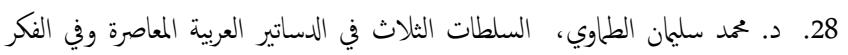

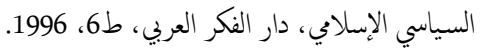

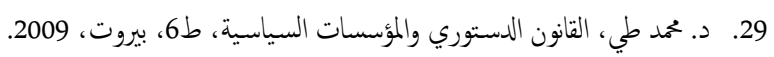

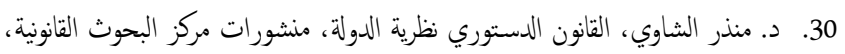
بغداد، 1981.

31. د. نعحان أحمد الخطيب، الوجيز في النظم السياسية، دائرة الثقافة للنشر والتوزيع، ط2، 2011.

32. د. يحيى الجمل، الأنظمة السياسية المعاصرة، دار النهضة العربية، القاهرة.

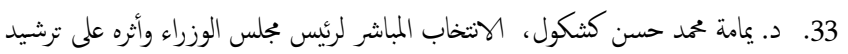

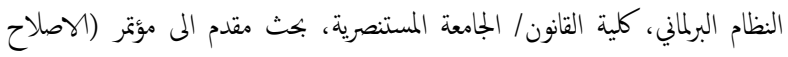

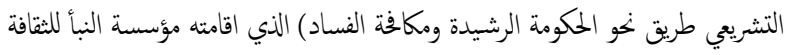

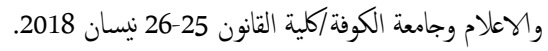

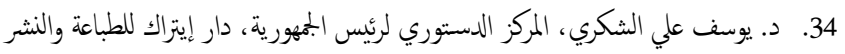

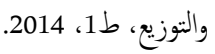
35. د.علي محسن محدي ، حدود السلطة التنفيذية في النظام البرلماني، الرواد للطباعة

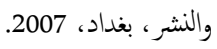




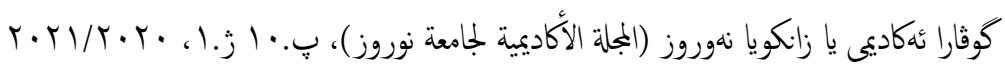

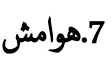

1 - Elliot Bulmer, Government Formation and Removal Mechanisms, International IDEA Constitution-Building Primer, 2017, p7.

2 - Kemal Gözler, Kemal Gözler, Anayasa Hukukunun Genel Teorisi, Bursa, Ekin, Cilt I, 2010, p 589.

3 - Oğuz Ersöz, Hükümet Sistemlerin Gelen Teorisi Ve Türkye Analizi, p 17, see: http://web.ebaro.web.tr/uploads/45/Etkinlikler/2015/2_Oguz_Ersoz.pdf .

$$
4 \text { ) د. محمد طي، القانون الدستوري والمؤسسات السياسية، ط6، بيروت، 2009، ص200. }
$$

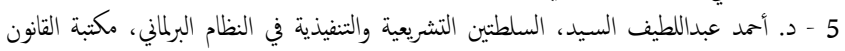

والإقتصاد، السعودية - رياض، 6 6 ) د. محمد رفعت عبدالوهاب، النظم السياسية، دار الجامعية الجديدة للنشر، 2014، 2007، ص299-

.300

$$
7 \text { 7 } 7 \text { د. محد رفعت عبدالوهاب، المصدر السابت، ص3200. }
$$

.7 - Elliot Bulmer,Op.Cit.p ${ }^{8}$

9 ) د. ابراهيم درويش، النظام السياسي، دراسة فلسفية تحليلية، دار النهضة العربية، القاهرة، 1968، ص 340.

10 ) د. عبدالميد متولي، القانون الدستوري والأنظمة السياسية، منشأة المعارف بالأسكندرية، 1993، ص335. 11 - الفقرة ثانياً من المادة ا من النظام الداخلي لمجلس الوزراء العراقي 785 الماد 2019.

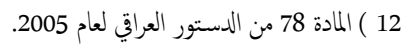

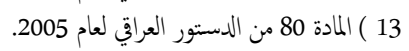
- Kemal Gözler, Op.Cit , p590. 14 Op.Cit, p591.15

16 ) د. حازم صادق، سلطة رئس الدولة بين النظامين البرلماني والرئاسي، الهيئة المصرية العامة

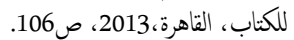

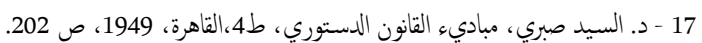

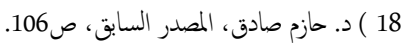
19 - عوض اللمون، المركز الدستوري لرئيس الحكومة في النظام الدستوري الأردني، مجلة علوم المان

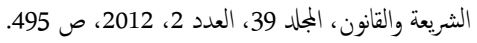
20 - ابراهيم عبدالعرزيز شيحا، النظم السياسية والقانون الدستوري، منشأة المعارف بالأسكندرية، 2000، ص ص 214 21 - د. علي مجيد العكيلي، الحدود الدستورية للسلطة التنفيذية في الدساتير المعاصرة، المركز العربي

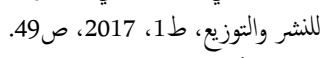
22 - د. أحمد سلامة بدر، الاختصاص التشريعي لرئيس الدولة في النظام البرلماني، دار النهضة العربية،

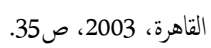
23 - ينظر: د. فتحي فكري، جواز الجمع بين العضوية البرلمانية والوظائف والأنشطة الأخرى، دار النهضة العربية، 1994، ص 11 - 18 - 18 فيني فكري، 24 - د. عصام سليمان، الأنظمة البرلمانية بين النظرية والتطبيق، منشورات الحلبي الحقوقية، ط1، النه

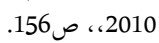
25 - الفقرة أولاً من المادة 8 من قانون مجلس التواب وتشكيلاته في العراق.

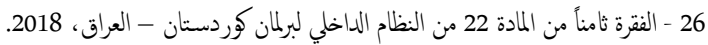

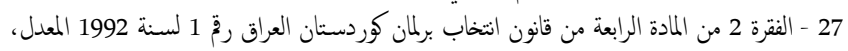
طبعة ايلول، 2016.

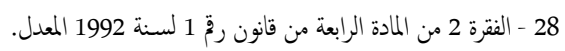

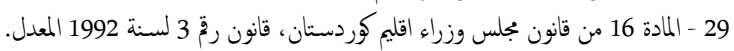

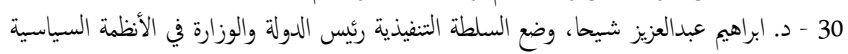

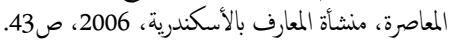
- Oğuz Ersöz,Op.cit.p19. ${ }^{31}$

32 - الفقرة 4 من المادة 56 من قانون رقُ 1سنة 1992المعدل، ونص المادة الخامسة من قانون رقز 3 لسنة 1992 المعدل بأنه يكون منح الثقة باعضاء المجلس فرداً فرداً بطلب من من الرئيس.

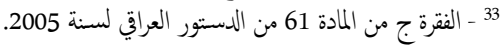

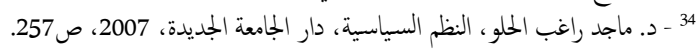

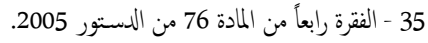

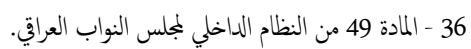

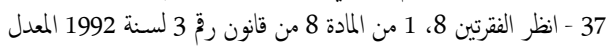

$$
\begin{aligned}
& \text { 19. قرار } 7 \text { الصادر من برلمان اقليم كوردستان في } 11 \text { - } 6 \text { - } 2019 \text { ف } 2019 .
\end{aligned}
$$

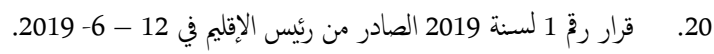

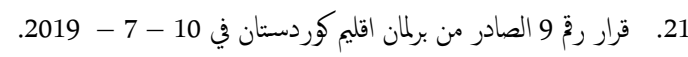

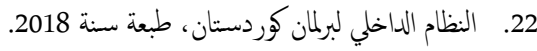

$$
\begin{aligned}
& \text { 23. قانون مجلس النواب وتشكيلاته في العراق. } \\
& \text { 24. النظام الداخلي لمجلس النواب العراقي. } \\
& \text { 25. النظام الداخلي لمجلس الوزراء العراقي } 2019 .
\end{aligned}
$$

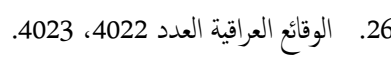

$$
\begin{aligned}
& \text { 27. رسالة السيد رئيس الجمهورية الى رئيس مجلس النواب العراقي في 2019/12/29. }
\end{aligned}
$$

4.5 باللغة الإنكليزية

1. Elliot Bulmer, Government Formation and Removal Mechanisms, International IDEA Constitution-Building Primer, 2017.

2. Mikitaka Musyama and Benjamin Niblade, Mikitaka Masuyama Japan: The Prime Minister and the Japanese Diet, The Journal of Legislative Studies, Vol.10, No.2/3, Summer/Autumn 2004.

\section{5 باللغة التركة}

1. Kemal Gözler, Kemal Gözler, Anayasa Hukukunun Genel Teorisi, Bursa, Ekin, Cilt I, 2010.

2. Oğuz Ersöz, Hükümet Sistemlerin Gelen Teorisi Ve Türkye Analizi, p 17, see:

http://web.ebaro.web.tr/uploads/45/Etkinlikler/2015/2_Oguz_E rsoz.pdf.

3. Sezen Kama, Parlamenter Hükümet Sistemi Olarak "Westminster Modeli", Britanya Örneği Üzerine Bir Deneme, see: https://www.academia.edu/37569399/Parlamenter.

\section{5 المصادرالأكترونية}

1. الحكومة، النظام الحكوي السويدي، دراسة نشرت من قبل المعهد السويدي،على الموقع .

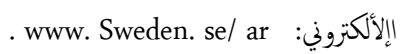

2. Oğuz Ersöz, Hükümet Sistemlerin Gelen Teorisi Ve Türkye Analizi, p 17, see: http://web.e-

baro.web.tr/uploads/45/Etkinlikler/2015/2_Oguz_Ersoz.pdf . 3. د. علي محدي، في اختيار رئيس الحكومة، على الموقع الآتي :

- في 15 https://www.radionawa.com/wtar-detail.aspx?jimare=297 $.2019-12$ 4. الاشتراكيون يصوتون في البرلمان لصالح تشكيل حكومة أقلية برئاسة ماريانو راخوي في إسبانيا: https://www.bbc.com/arabic/world/2016/10/161023_spain_rajo y_minority_government_socialists_vote

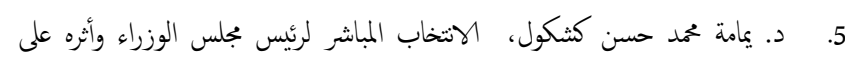

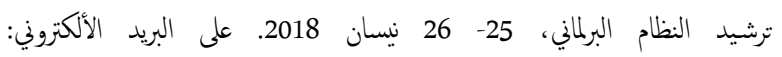
https://m.annabaa.org/arabic/studies/15846 


$$
78 \text { - } 77 \text { - د. عام ساديليان، المصدر السابق، ص20. }
$$

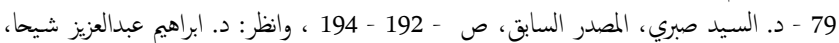

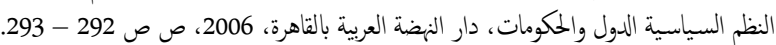
80 - 81 - أيرك برندت، المصدر السابق، ص250.

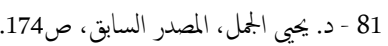

82 - د. علي محدي، في اختيار رئيس الحكومة، على الموقع الآتي : 81

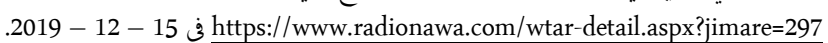

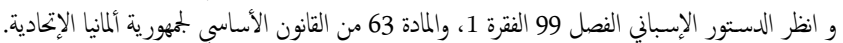

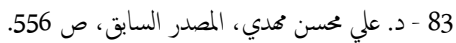

- Sezen Kama, Parlamenter Hükümet Sistemi Olarak "Westminster 84 Modeli” , Britanya Örneği Üzerine Bir Deneme, Ar. Gör., İstanbul Medeniyet Üniversitesi Hukuk Fakültesi Anayasa Hukuku Anabilim Dalı, p

174.

85 - الاشتراكيون يصوتون في البرلمان لصالخ تشكيل حكومة أقلية برئاسة ماريانو راخوي في إسبانيا: الألكتروني

https://www.bbc.com/arabic/world/2016/10/161023_spain_rajoy_minority government_socialists_vote

86 ـ المادة 63 من القانون الأساسي لمجهورية ألمانيا الاتحادية، 1949 ـالمادية.

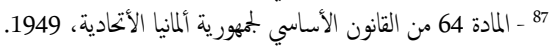
88 - المواد 4 و 54 و 6 من من دستور السويد للام المام 1974.

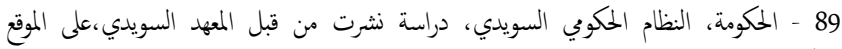
الإلكتروني

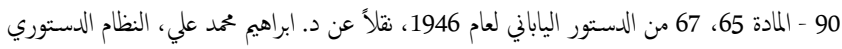

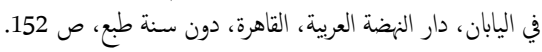

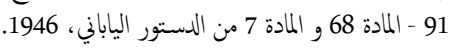

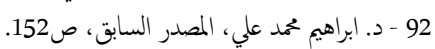

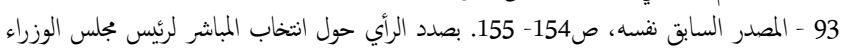

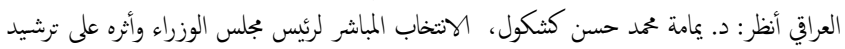

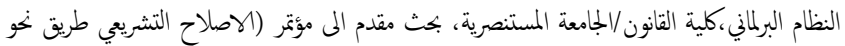

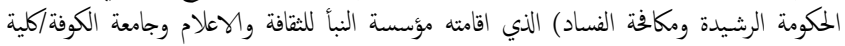
القانون . https://m.annabaa.org/arabic/studies/15846

94 - Mikitaka Musyama and Benjamin Niblade, Mikitaka Masuyama Japan: The Prime Minister and the Japanese Diet, The Journal of Legislative Studies, Vol.10, No.2/3, Summer/Autumn 2004, p252.

95 -Ibid, p 253.

96 - الفقرة أولاً من المادة 77 من الدستور العراقي لعام 97 - 2005.

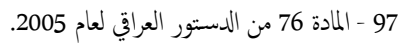

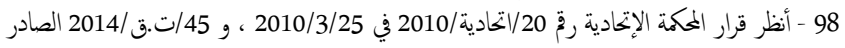

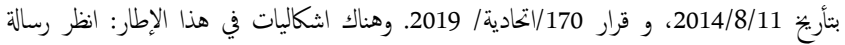
السيد رئيس الجمهورية المى رئيس مجلس النواب العراقي في 2019/12/29.

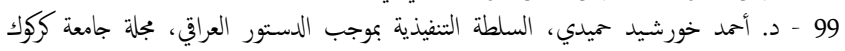

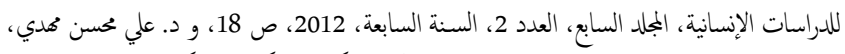

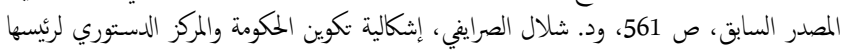

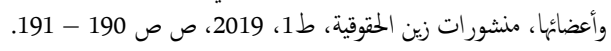

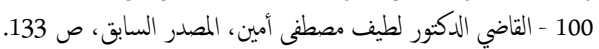

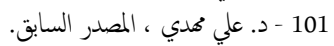

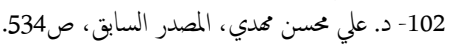

103 - أ، ب، ثامنأ، المادة 61 من المادستور العراقي.

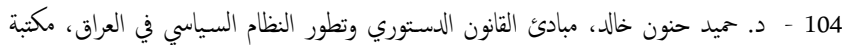

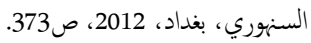
105 - أنظر الوقائع العراقية العدد 4022، صنداد، 4023.
38 - د. عبدالميد متولي، المصدر السابق، ص317.

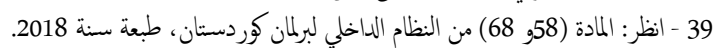
- Kemal Gözler, Op.Cit, P591 - 592.40 41 - د. ابراهيم درويش، المصدر السابق، ص242.40 - 242

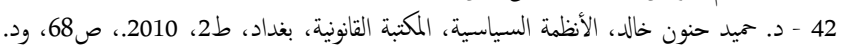

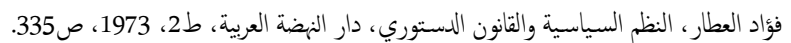

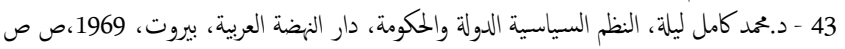
$.946-945$

44 - د. يجيى الجمل، الأظمة السياسية المعاصرة، دار النهضة العربية، القاهرة، ص174 - 4545

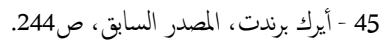

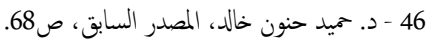

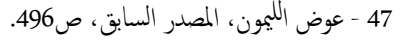

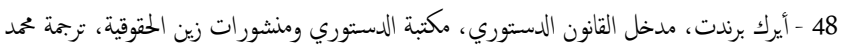

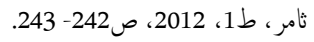
49 - المادة (62، 65 65) من القانون الأساسي لمجهورية المانيا الأتحادية، 1942 - 1949.

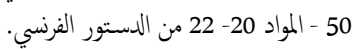

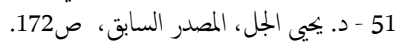

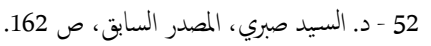
-Elliot Bulmer, Op,Cit, P8.53 54 - د.علي محسن محدي ، حدود السلطة التنفيذية في النظام البرلماني، الرواد للطباعة والنشر، بغداد، 2007، ص255. 55 - القاضي الدكتور لطيف مصطفى أمين، العلاقة بين رئيس الدولة ورئيس الحكومة في النظام

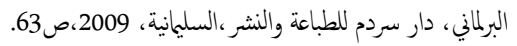

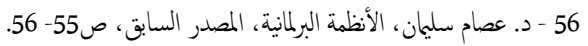

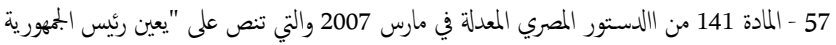

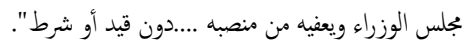

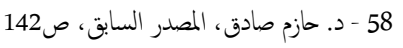

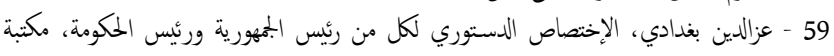

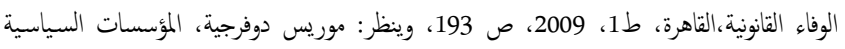

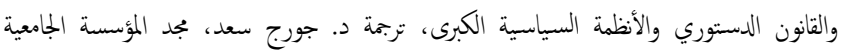

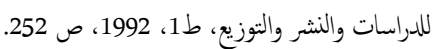
60 - المادة 12 من الدستور النوويج.

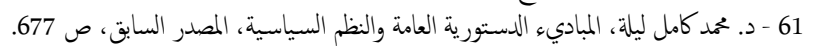
62 - 61 - د. منذر الشاوي، القانون الدستوري نظرية الدولة، منشورات مركز البحوث المنادية القانونية، بغداد، 1981 198 صن 179 63 - أنور مصطفى الأهواني، رئيس الدولة في النظام الديمقراطي، رسالة دكتورا مقدمة لكلية الحقوق

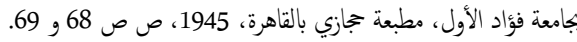

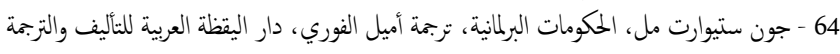

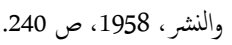

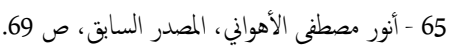

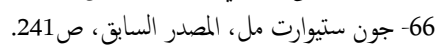

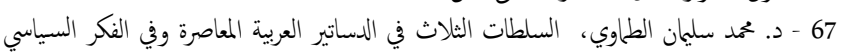

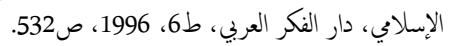

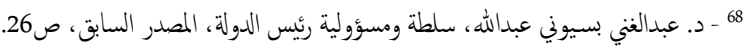

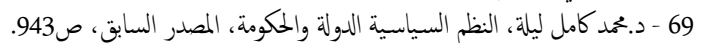
- Kemal Gözler, Op.Cit, P 592. 70

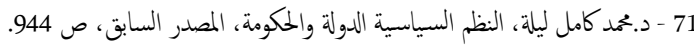

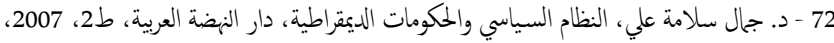
ص162. - n 73 - أنظر: د. حيدر المولي، التضامن الوزاري والحكومات الأئلافية، منشورات زين الحقوقية، ط1،

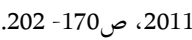

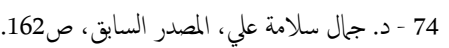

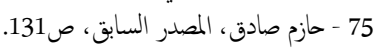

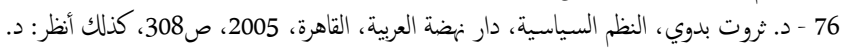

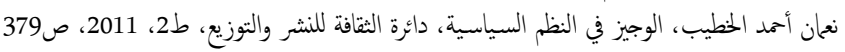
$.432-$ 
135 - قرار منح الثقة لرئيس الحكومة ونائبه والوزراء رقٌ 35 الصادر من برلمان كوردستان في

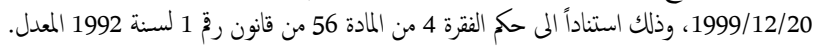

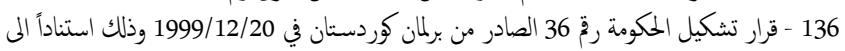

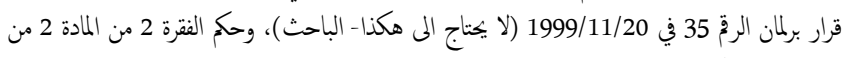

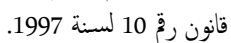

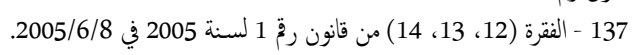

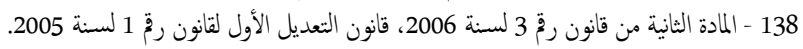

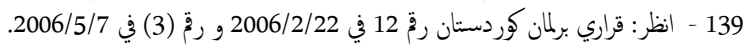

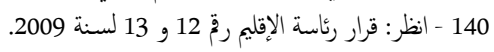

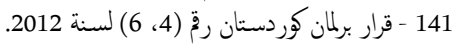

142 - قانون رقٌ (1) لسنة 2014، قانون التعديل (5 ) لقانون رئاسة الإقليم رقّ 1 لسنة 2005

143- قرار 7 في 11 - 6 - 144 - 2019 الصادر من برلمان اقليم كوردستان.

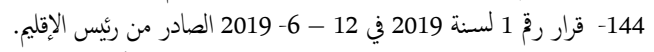

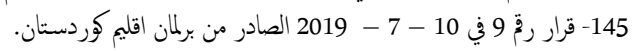

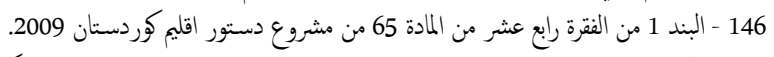

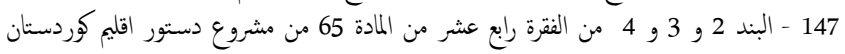

2009

. - Oğuz Ersöz, Op.cit.p20148

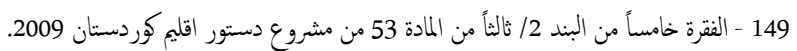

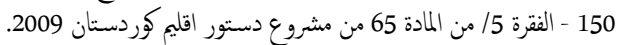

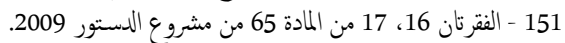
-Elliot Bulmer, op.cit,p9.152 153 - الفقرة رابعا من المادة 10 من قانون رئاسة اقليم كوردستان رق 1 لسنة 2005 المعدل.
106 - د. أحمد عبداللطيف ابراهيم السيد، دور رئيس الدولة في النظام السياسي الديمقراطي النيابي

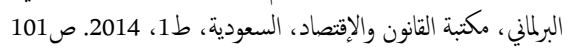

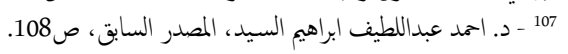

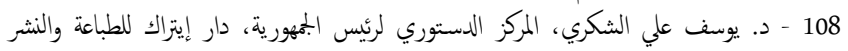

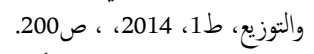
109 - المادة 56 من الدستور الكويتي. 110 - المادة 72 من المادة الدستور القطري.

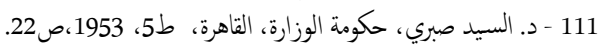

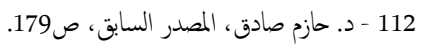

113 - د. أحمد عبداللطيف ابراهيم السيد، المصدر السابق، ص ص صالم 112.

114 -Elliot Bulmer, Op.Cit, p9.

115

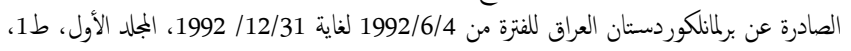

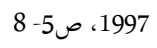

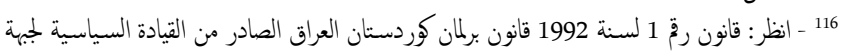

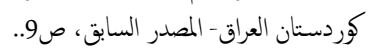

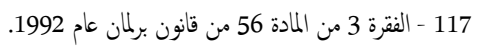

118 - الفترة 117 من الماندة 11 من من قادة قانون انتخاب قائد المركة النحريرية الكوردية رقّ 2 لسنة 1992 والتي تم الغاءها بموجب قانون.

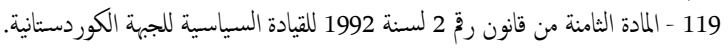

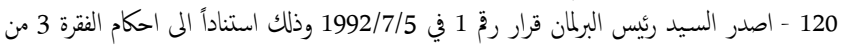

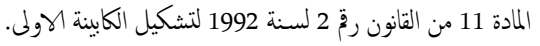

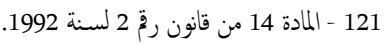

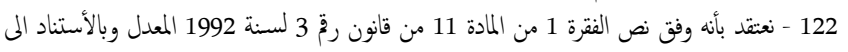

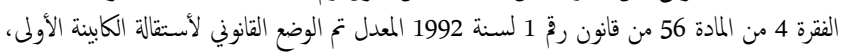

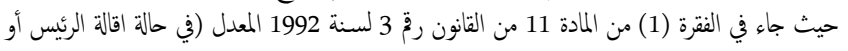

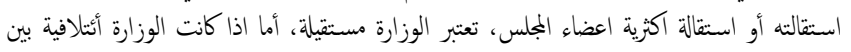

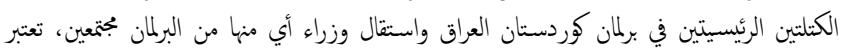
الوزارة مستقيلة ايضاً). 123 - القرار رقة 22 الصادر من البرلمان في 1993/4/11، وذلك استناداً المى الفقرة 3 من المادة 56 من

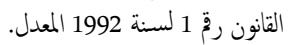

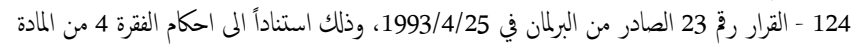

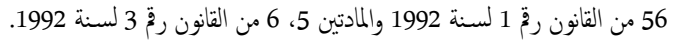

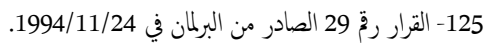

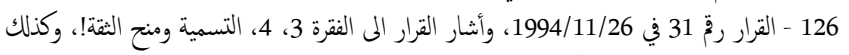

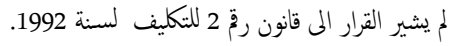

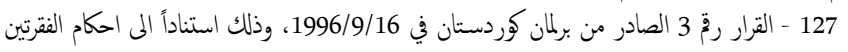

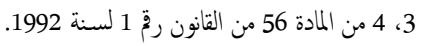

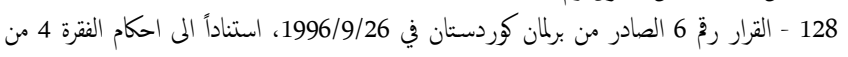

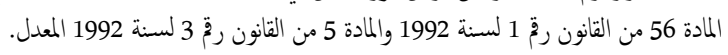

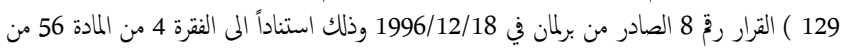
قانون رقٌ 1 لسنة 1992 السرار 1990. 130 - نص الفقرة 1 من المادة 8 من قانون رخ 3 لسنة 1992 المعدل، يمارس مجلس الوزراء صلاحية

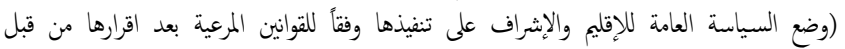
برلمانكوردستان العراق)..

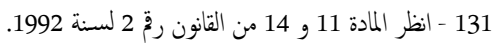

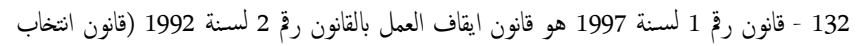
قائد الحركة التحريرية الكوردية).

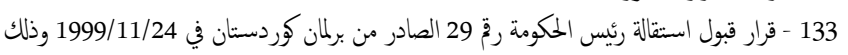

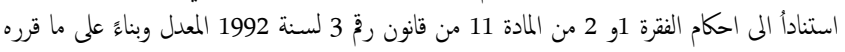

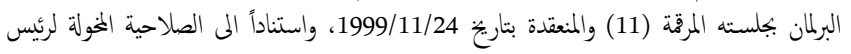

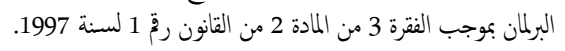

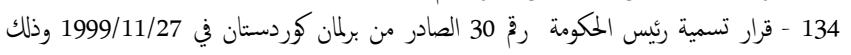

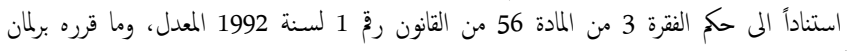

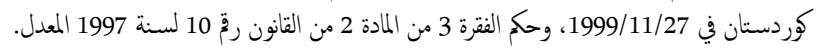

